\title{
The hydrothermal alkaline alteration of potassium feldspar: a nanometer-scale investigation of the orthoclase interface
}

Roland Hellmann*a, Yuanyuan Zhai ${ }^{b, c, d, 1}$, Eric Robin ${ }^{\mathrm{e}}$, Nathaniel Findling ${ }^{\mathrm{a}}$, Sathish Mayanna ${ }^{\mathrm{f}, 2}$, Richard Wirth $^{\mathrm{f}}$, Anja Schreiber ${ }^{\mathrm{f}}$, Martiane Cabiég, Qingdong Zeng ${ }^{\mathrm{b}, \mathrm{c}, \mathrm{d}}$, Shanke Liu ${ }^{\mathrm{b}, \mathrm{c}}$, Jianming Liu ${ }^{\mathrm{b}, \mathrm{c}, \mathrm{d}, 3}$.

a Université Grenoble Alpes and CNRS, ISTerre, F-38058 Grenoble Cedex 9, France

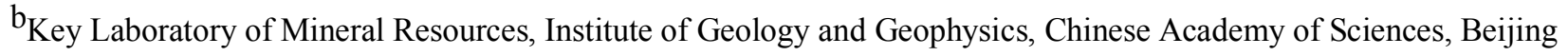
100029, China

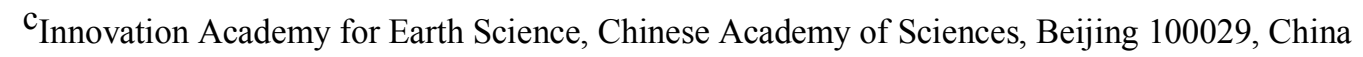

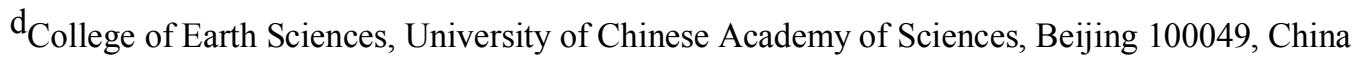

e Université Grenoble Alpes, IRIG, MEM, CEA, Grenoble, France

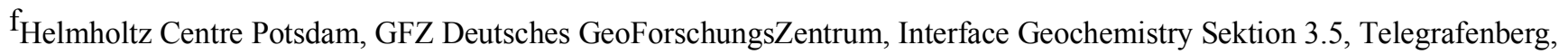
D-14473 Potsdam, Germany

g Aix Marseille Université, CNRS, Centrale Marseille, FSCM (FR1739), CP2M, F-13397 Marseille, France

1 current address: Shenzhen Xinhua Middle School, Shenzhen 518109, China

2 current address: Carl Zeiss Microscopy GmbH, D-73447 Oberkochen, Germany

3 retired

3 Key words: orthoclase feldspar alkaline hydrothermal alteration, coupled interfacial dissolution4 reprecipitation (CIDR), analytical transmission electron microscopy (TEM), energy filtered TEM 5 (EFTEM), TEM-EDXS, electron energy loss spectroscopy (EELS), orthoclase-fluid interface, secondary 6 cement phases, $\mathrm{CASH}$ and $\mathrm{CSH}, \mathrm{K}$ fertilizer

"to whom correspondence may be addressed.

1 Email: roland.hellmann@univ-grenoble-alpes.fr 
Potassium feldspars $\left(\mathrm{KAlSi}_{3} \mathrm{O}_{8}\right)$ are ubiquitous minerals in the Earth's upper crust. This family of minerals has been the subject of numerous experimental and theoretical investigations concerning their dissolution kinetics and the mechanisms controlling chemical alteration at acid and neutral $\mathrm{pH}$, and at temperatures ranging from ambient to hydrothermal conditions. On the other hand, considerably less research on the dissolution behavior of K-feldspars has been carried out at alkaline conditions, in particular at $\mathrm{pH}>9$ and elevated temperatures. Filling in this gap in knowledge is the major motivation for this study. More specifically, we wanted to document and understand how the K-feldspar interface structurally and chemically evolves during alteration in order to determine the mechanism of dissolution. In this study we examined interfaces of orthoclase samples that were altered in separate experiments in a $\mathrm{Ca}(\mathrm{OH})_{2}-\mathrm{H}_{2} \mathrm{O}$ solution $\left(\mathrm{pH}_{25^{\circ} \mathrm{C}} 12.4\right)$ at $190{ }^{\circ} \mathrm{C}$ for 24 hours. We used a combination of focused ion beam (FIB) milling and advanced analytical transmission electron microscopy (TEM) techniques to investigate the structure and chemistry of the near surface region of post-reaction grains, with particular attention being given to the fluid-solid interface. Even though each grain diminishes in volume due to dissolution, high-resolution TEM imaging indicates that the feldspar structure itself remains completely intact and crystalline, as evidenced by lattice fringes that abruptly terminate at the grain edge. Nanometer-scale chemical composition measurements and mapping by TEM-EDXS (energy dispersive X-ray spectroscopy) and EFTEM (energy filtered TEM) show that the chemistry of the parent feldspar also remains unchanged at the interface. In particular, there is no evidence for the incursion of $\mathrm{Ca}$ from the fluid solvent into the structure, either by interdiffusion or by a replacement process. Taken together, the TEM observations point to a sharp chemical reaction front characterized by the congruent (i.e. stoichiometric) release of all elements from the feldspar structure.

Nanometer-scale measurements by high resolution analytical TEM also reveal that a surface alteration layer (SAL) of amorphous material forms in situ at the expense of the feldspar structure. The interface demarcates a spatially coincident and nm-sharp chemical and structural discontinuity between the parent feldspar and the amorphous phase. The amorphous SAL has a variable thickness, from under $10 \mathrm{~nm}$ up to $\sim 200 \mathrm{~nm}$. This is likely one of the first observed occurrences of a significant surface amorphous layer on feldspar due to alteration in an alkaline solvent. The lack of a gap between the two phases points to an interfacial dissolution-reprecipitation process that continuously operates during hydrothermal alteration, and mostly likely right from the onset of contact with the fluid. After the initial formation of the amorphous layer, a 1-2 $\mu \mathrm{m}$-thick porous amalgam of secondary crystalline phases comprised of calcite, tobermorite, and hydrogrossular, as well as other minor phases, precipitated over 
the SAL. These authigenic crystalline minerals formed during the experiment (hydrothermal alteration, followed by fluid loss due to evaporation) by a classical thermodynamically-controlled precipitation process as the reactor bulk fluid became increasingly concentrated.

We propose that a coupled interfacial dissolution-reprecipitation (CIDR) mechanism best explains the chemical and structural properties of the interface and the formation of an amorphous surface layer. In fact, many recent studies postulate that a CIDR process controls feldspar dissolution and the formation of SALs at acid and circumneutral $\mathrm{pH}$ over a wide range of temperatures. Combining these previous results with our new observations supports the idea that a unique and unifying mechanism likely controls chemical alteration of feldspars in all aqueous fluids.

\section{INTRODUCTION}

\subsection{Research goals}

The feldspar-water system is arguably one of the most important in the earth sciences, in particular with respect to chemical weathering associated with water-rock interactions. This is primarily due to the preponderance of feldspar minerals in the upper continental crust and at earth's surface (Klein and Philpotts, 2017). Feldspars are chemically robust framework silicates and thus dissolve very slowly, with the kinetics of dissolution depending strongly on $\mathrm{pH}$ and temperature. While the aqueous alteration of feldspars has been extensively investigated experimentally and theoretically, the overwhelming majority of studies have focused on alteration at conditions encompassing acid, circumneutral, and weak alkaline $\mathrm{pH}$ conditions (i.e., $\mathrm{pH}$ 1-9), and at temperatures less than $100{ }^{\circ} \mathrm{C}$. There are several reviews of feldspar dissolution rates as a function of $\mathrm{pH}$ at ambient conditions, e.g., Blum and Stillings, 1995; Bandstra et al., 2008; at elevated temperatures up to hydrothermal conditions, see, e.g., Hellmann, 1994; Yuan et al., 2019; and references therein. The review of feldspar alteration by Yuan et al. (2019) is a good starting point for a synopsis of both new and not-so-recent work concerning both dissolution rates and mechanisms of feldspar alteration reactions in aqueous fluids.

In this study we examine post-reaction solid-fluid interfaces of alkali feldspars in order to elucidate the mechanism of chemical alteration in alkaline aqueous fluids with a very high $\mathrm{pH}$. As discussed in more detail in section 1.3, it is at these conditions where there is a real need for more experimental data, which in turn explains one of the motivations for our research. Moreover, we wanted to document and understand how the crystal structure evolves both structurally and chemically when in contact with a very basic $\mathrm{pH}$ solution at elevated temperature. Many studies have reported the formation 
of surface altered layers (SALs) on feldspars undergoing chemical alteration at acid, circumneutral, and mild alkaline conditions (e.g., Hellmann et al. 2003, 2012; and references therein), We note, however, that literature data on feldspar hydrolysis at basic $\mathrm{pH}$ conditions $(>\mathrm{pH} 9)$ are not numerous, this in particular being true for temperatures above $100{ }^{\circ} \mathrm{C}$. For this reason we posed the question whether this interfacial process, in other words SAL formation, also operates when an alkali feldspar is exposed to an aggressive basic $\mathrm{pH}$ solution at elevated temperature. In response to this question, the present research is among the first that has focused on a detailed structural and chemical examination of feldspar interfaces after basic $\mathrm{pH}$ alteration using high-resolution analytical TEM techniques.

The overarching goal of our study was to focus on nanometer-scale TEM measurements to characterize structural and chemical changes to the interfacial region that encompasses the near surface of the primary feldspar and abutting authigenic secondary phases. We were in particular interested in two elements, $\mathrm{K}$ and $\mathrm{Ca}$. The behavior of $\mathrm{K}$ is fundamental, as it is a good tracer element for following the overall hydrothermal alteration process, starting with its release during dissolution of the parent feldspar, and then understanding its distribution with respect to the precipitation of secondary authigenic phases (see e.g., Zhai et al., 2021). On the other hand, determining the mobility and distribution of $\mathrm{Ca}$ is primordial since $\mathrm{Ca}(\mathrm{OH})_{2}$ makes up the solvent, and thus it is important to measure its distribution at high spatial resolution in order to determine whether or not it penetrates into the orthoclase structure. In addition, important framework elements, such as $\mathrm{Si}, \mathrm{Al}$, and $\mathrm{O}$, were also measured by TEM. Taken together, our TEM data provided us with the means to propose an operative mechanism at the nanometer-scale for K-feldspar alteration at basic $\mathrm{pH}$.

Even though the present research is uniquely devoted to orthoclase feldspar, it is worth reiterating that there are 3 common alkali feldspar polymorphs that share the same nominal formula, $\mathrm{KAlSi}_{3} \mathrm{O}_{8}$. However, their atomic structures are not identical. Sanidine is the polymorph that forms at the highest temperature and fastest cooling rates, whereas orthoclase and microcline crystallize at lower temperatures and are characterized by much slower cooling rates. The temperature and rate of crystallization affects the degree of $\mathrm{Al} / \mathrm{Si}$ ordering on the tetrahedral sites, with sanidine displaying the highest disorder, and microcline the lowest. Both sanidine and orthoclase crystallize in the monoclinic system (H-M, class $2 / \mathrm{m})$, while microcline crystallizes in the triclinic system (class $\overline{1})$. Classical studies, such as by Brown and Parsons, 1989, have addressed important processes that include ordering rates and phase transformations of the various K-feldspar polymorphs. These phenomena are intimately related to the creation of internal microstructures, which in turn can affect global dissolution behavior. While important for controlling the overall kinetics of K-feldspar dissolution, quantifying the effects of crystallographic structures at the micrometer to sub-micrometer-scale, as well as the degree of $\mathrm{Al} / \mathrm{Si}$ 
131 ordering, was not an objective of this study (for the effects of ordering on dissolution, see, e.g., Yang et 132 al., 2013, 2014a,b). In addition, a detailed mineralogical-crystallographic characterization of the 133 hydrothermal secondary products was also not carried out here. Nonetheless, another study on 134 hydrothermally altered microcline and sanidine focuses on the distribution and concentrations of 135 released $\mathrm{K}$ in secondary authigenic phases (Zhai et al., 2021).

\subsection{Brief review of surface alteration processes}

One of the key aspects for elucidating the mechanism of dissolution of any primary crystalline or glassy phase is a detailed understanding of surface altered layers that typically form in situ on a retreating (dissolving) surface. This involves using high-resolution analytical techniques in order to measure their chemistry and structure, as well as the respective interfacial gradients with the parent phase (e.g., see Hellmann et al., 2003, 2012, 2015). These layers are amorphous and generally have a chemical composition distinct from the parent mineral (or glass). Many recent studies on feldspars altered at acid to circumneutral $\mathrm{pH}$ conditions, in both the laboratory and in the field, have documented their presence using TEM techniques (e.g., Hellmann et al., 2003, 2012; Lee et al., 2007, 2008; references therein). In fact, nearly all polycationic silicate minerals have the potential to develop a SAL when in contact with an aqueous fluid (Hellmann et al., 2012, Ruiz-Agudo et al., 2012). Related to SAL formation is an equivalent process termed mineral-mineral replacement, but in this case a secondary mineral replaces the primary mineral (see reviews in Putnis, 2009, 2014).

Traditional thinking regarding both SAL formation and mineral-mineral replacement posits that they are controlled by an interdiffusion process between preferentially leached cations in the parent solid and certain charge-compensating cations (including $\mathrm{H}_{3} \mathrm{O}^{+}$) in the bulk fluid (see reviews in Hellmann et al., 2012; Yuan et al., 2019). However, based on the application of relatively new and advanced analytical techniques to altered samples prepared in cross-section by ultramicrotomy (e.g., Thomassin et al., 1995; Buck et al., 2000; Hellmann et al., 2003) and focused ion beam milling-FIB (e.g. Wirth, 2004; Hellmann et al., 2012), the theory of preferential cation leaching controlled by interdiffusion has become increasingly doubtful. In fact, research over the past two decades promotes an alternative theory that is gaining widespread acceptance. It is based on a coupled interfacial process that links dissolution of the parent mineral with the synchronous interfacial reprecipitation of a secondary phase, which can be either amorphous (SAL) or crystalline. In the latter case, this is governed by a pseudomorphic replacement process (Putnis, 2002, 2009, 2014; King et al., 2011). Some minerals, in particular feldspars, can develop an amorphous SAL (Hellmann, et al., 2003, 2012), or alternatively, show replacement by a feldspar of another composition (O’Neil and Taylor, 1967; Labotka et al., 2004; Hövelmann et al., 
2010). Both the nature of the primary mineral and the physicochemical conditions of the fluid determine

165 in large part which process occurs (see details in Hellmann et al., 2012- Fig. 4). It is important that SALs and mineral-mineral replacement are not confused with the classical precipitation of secondary phases onto a mineral surface from a chemically oversaturated bulk fluid. These points are discussed in more detail further on.

\subsection{Previous Work}

It has commonly been assumed that feldspars, and silicate minerals in general, dissolve 'more-orless' congruently at ambient temperatures and at neutral to basic $\mathrm{pH}$ conditions, without the formation of SALs. In regard to feldspars, this is based on aqueous chemistry measurements showing that nonstoichiometric dissolution is most pronounced at acid $\mathrm{pH}$ conditions, and significantly less at circumneutral and basic pH (Chou and Wollast, 1985; Holdren and Speyer, 1985; at elevated temperatures, see e.g., Hellmann et al., 1989; Hellmann, 1999a,b). With the application of relatively new solid-state analysis techniques in the geosciences, the formation of SALs on feldspars and other silicates received much attention in the 1990's and the decade thereafter. The pioneering studies by Petit and Dran applied several types of surface sensitive multi-eV ion beam methods, such as resonant nuclear reaction analysis (RNRA), to obtain $\mathrm{H}$ and cation depth profiles of chemically altered feldspars and other silicate minerals and glasses (Petit et al., 1989, 1990a,b; Dran et al., 1988; Hellmann et al., 1997). Casey and co-workers applied elastic recoil detection (ERD) and Rutherford backscattering spectroscopy (RBS) to determine $\mathrm{H}$ and cation depth profiles on labradorite feldspar surfaces after reaction at ambient or near-ambient temperatures over a wide range of solvent $\mathrm{pH}$ (Casey et al. 1988, Casey et al., 1989a,b; Arnold et al., 2002).

Other surface-sensitive techniques, such as X-ray photoelectron spectroscopy (XPS) (Hellmann et al., 1990; Chen et al., 2000) and secondary ion mass spectrometry (SIMS) (Schweda et al., 1997; Nesbitt and Muir, 1988; Nugent et al., 1998) were also used to study cation depletion in reacted feldspars as a function of $\mathrm{pH}$ and temperature. Other lesser known techniques, such as high-resolution in-situ X-ray reflectivity (XR) and ex-situ X-ray reflection interface microscopy (XRIM), were used by Fenter and colleagues to probe near-surface orthoclase chemistry after reaction at 25 and $50{ }^{\circ} \mathrm{C}$ in solutions at acid, neutral, and very basic $\mathrm{pH}$ (Fenter et al., 2000, 2010; Teng et al., 2001).

When considered together, data from most of the above-cited studies indicate that changes in the near surface of feldspars do occur during chemical alteration, both in terms of chemistry and the formation of an amorphous SAL. With the exception of alteration at acid $\mathrm{pH}$ conditions, these SALS are 
197 former feldspar structure. Moreover, some of the above studies concluded that feldspars dissolve more 198 or less congruently at $\leq 50{ }^{\circ} \mathrm{C}$ at neutral to basic $\mathrm{pH}$ conditions, and that dissolution only proceeds at the 199 immediate surface, layer by layer. While SALs are undoubtedly thin at these $\mathrm{pHs}$ and low temperatures, 200 the top-down surface analytical techniques with large beam foot prints that were used in the 1990's and 201 early 2000's were also limited in sensitivity and/or spatial resolution. For this reason, the study of 202 reacted mineral interfaces prepared in cross section by ultramicrotomy (Thomassin et al., 1995; Hellmann et al., 2003) or by FIB (e.g., Wirth, 2004) with Å-resolved TEM techniques has proven to be a breakthrough and an enormous advantage for better characterizing altered surfaces and understanding how they form, see e.g., Buck et al., 2000; Hellmann et al., 2003.

Up to the end of the 1990s only a handful of studies had been dedicated to alkaline hydrothermal 207 alteration of feldspars, in particular the detailed exploration of SALs and their mechanism of formation. One pioneering study used XPS and angle-resolved XPS (ARXPS) to measure the near-surface chemistry of albite $\left(\mathrm{NaAlSi}_{3} \mathrm{O}_{8}\right)$ that had been subjected to hydrothermal alteration at $225{ }^{\circ} \mathrm{C}$ in a $\mathrm{pH}_{\left(25^{\circ} \mathrm{C}\right)} 10.1$ solution (Hellmann et al., 1990). This study showed, via non-stoichiometric near-surface $\mathrm{Al} / \mathrm{Si}, \mathrm{Na} / \mathrm{Si}$, and $\mathrm{O} / \mathrm{Si}$ ratios, that $\mathrm{SALs}$ with thicknesses of many tens of $\mathrm{nm}$ form at these conditions. The possibility of relatively thick SALs developing during alteration at basic $\mathrm{pH}$ and hydrothermal conditions was further supported by results from an experimental study by Hellmann (1995), based on alkaline dissolution of albite feldspars at $\mathrm{pH}_{\left(25^{\circ} \mathrm{C}\right)} 10.0$ and 12.0 at hydrothermal conditions $(100,200$, and $300{ }^{\circ} \mathrm{C}$ ). Even though only aqueous solution compositions were measured, a generalized and significant non-stoichiometry was reported. These results are tantalizing, in that they provide indirect evidence for the formation of non-negligible SALs at elevated $T$ and $\mathrm{pH}$ conditions. Even though these experiments used pure albite feldspar $\left(\mathrm{NaAlSi}_{3} \mathrm{O}_{8}\right)$, the aqueous results underline a key point, namely that $\mathrm{Na}, \mathrm{Al}$, and $\mathrm{Si}$, and by analogy $\mathrm{K}, \mathrm{Al}$, and $\mathrm{Si}$ in a $\mathrm{K}$-feldspar, can be considered to be mobile during hydrothermal alteration at basic $\mathrm{pH}$ conditions.

A study of the Jurassic Navajo Sandstone by Zhu et al. (2006) revealed that SALs can also form under natural conditions. TEM images show the presence of a naturally occurring $10 \mathrm{~nm}$-thick amorphous SAL that formed in situ on an alkali feldspar. The composition was not measured, but the authors postulate that it is K-deficient and Si-enriched. Even though the formation fluid was found to be mildly alkaline during borehole sampling, it is not known how the $\mathrm{pH}$ (and temperature) varied over geological time. Quite importantly, this example shows that SALs are not ephemeral features of dissolution, but can be stable over geologically long periods of time.

Over the past decade, there has been a resurgence of interest in the study of the chemical alteration of K-feldspars. The objective of many recent studies has been to use very aggressive basic $\mathrm{pH}$ fluids to 
chemically breakdown K-feldspars at hydrothermal conditions. The resulting secondary authigenic phases that are produced during chemical alteration are enriched in $\mathrm{K}$. This hydrothermal product can be used directly as a K-fertilizer on soils, and is increasingly considered to be a commercially viable substitute for traditional K-rich soluble salts, such as sylvite $(\mathrm{KCl})$. Such soluble salts are nearly all sourced in northern hemisphere countries (e.g., Belarus, Russia, Canada, Germany), making their longdistance transport to developing countries in the southern hemisphere financially prohibitive. The extraction of K-fertilizer from K-feldspars has a more than century-long history behind it, as described in Ciceri et al. (2015). Despite this, little is known on the exact mechanism controlling this process. It is interesting to note that over the past two decades several Chinese laboratories are spearheading this type of research (see review in, e.g., Ma et al, 2015). In these Chinese studies (and others), the generalized use of alkaline $\mathrm{pH}$ solutions to extract $\mathrm{K}$ is largely based on the economics of producing $\mathrm{CaO}$ from limestone, from which $\mathrm{Ca}(\mathrm{OH})_{2}$ is easily derived; there are also 'green chemistry' considerations that come into play (Ma et al., 2015; Ciceri et al., 2017a).

Recent studies focused on the alkaline hydrothermal extraction of $\mathrm{K}$ from K-feldspars have for the most part been centered on identifying and describing the secondary crystalline phases that are produced. Moreover, although none has studied in detail the mechanism that controls the chemical breakdown of the K-feldspar structure, a few have proposed scenarios on how this occurs. A study by $\mathrm{Su}$ et al. (2015) reacted $\mathrm{K}$-feldspar with aqueous $\mathrm{KOH}+\mathrm{NaOH}$ solutions $(8 \mathrm{M})$ at 240 and $280{ }^{\circ} \mathrm{C}$, where the mole fractions of $\mathrm{KOH}$ and $\mathrm{NaOH}$ were varied. These authors postulated congruent dissolution of the feldspar via an $\mathrm{OH}^{-}$mediated reaction:

$$
\mathrm{KAlSi}_{3} \mathrm{O}_{8}+2 \mathrm{H}_{2} \mathrm{O}+6 \mathrm{OH}^{-} \rightarrow \mathrm{Al}(\mathrm{OH})_{4}^{-}+3 \mathrm{H}_{2} \mathrm{SiO}_{4}^{2-}+\mathrm{K}^{+}
$$

251 The aqueous dissolution products on the right side of eqn. 1 consequently precipitate to form the 252 feldspathoidal mineral kalsilite, $\mathrm{KAlSiO}_{4}$. When the above reaction is carried out with $\mathrm{NaOH}$ solvent, sodium ions, in turn, reacting with $\mathrm{Al}(\mathrm{OH})_{4}^{-}$and $\mathrm{H}_{2} \mathrm{SiO}_{4}^{2-}$, lead to the precipitation of the feldspathoid hydroxycancrinite, $\mathrm{Na}_{8} \mathrm{Al}_{6} \mathrm{Si}_{6} \mathrm{O}_{24}(\mathrm{OH})_{2} \cdot 2 \mathrm{H}_{2} \mathrm{O}$. These crystalline phases formed as a dense amalgam of crystals, which presumably precipitated directly from an oversaturated bulk fluid (see Fig. 2, Su et al., 2015). The stoichiometric dissolution reaction detailed by Su et al. (2015) corresponds to the findings of Gautier et al. (1994), who observed that $\mathrm{Al}$ and $\mathrm{Si}$ were released congruently from a K-rich feldspar at $150^{\circ} \mathrm{C}$ and $\mathrm{pH}$ 9.0. Another study, by Liu et al. (2015), hydrolyzed K-feldspar (microcline) in $\mathrm{NaOH}$, $\mathrm{KOH}$, and $\mathrm{Ca}(\mathrm{OH})_{2}$ solutions at hydrothermal temperatures up to $220{ }^{\circ} \mathrm{C}$. They proposed a mineralmineral replacement process controlled by dissolution-precipitation, leading to the formation of hydrated Ca-Al-silicate phases. At $220{ }^{\circ} \mathrm{C}$ they described the overall reaction as: 
$2 \mathrm{KAlSi}_{3} \mathrm{O}_{8}+6.3525 \mathrm{Ca}(\mathrm{OH})_{2}+0.195 \mathrm{H}_{2} \mathrm{O} \rightarrow \mathrm{Ca}_{3} \mathrm{Al}_{2}\left(\mathrm{SiO}_{4}\right)_{1.53}(\mathrm{OH})_{5.88}+1.49 \mathrm{Ca}_{2.25}\left(\mathrm{Si}_{3} \mathrm{O}_{7.5}(\mathrm{OH})_{1.5}\right) \cdot \mathrm{H}_{2} \mathrm{O}+2 \mathrm{KOH}$ (2)

264 The above reaction, which proceeds via a transitional compound (not shown), results in the precipitation 265 of hydrogarnet and CSH phases (calcium-silicate-hydroxide). Even though the authors describe this as a mineral-mineral replacement reaction, they did not present evidence for pseudomorphic replacement of the feldspar, which is one of the defining characteristics of a true mineral-mineral replacement reaction (see review in Putnis 2009, see also, e.g., Harlov et al. 2002; Putnis and Mezger 2004; Putnis et al. 2005; Kasioptas et al. 2008). Thus, it would be more accurate to describe the overall reaction (Eq. 2) in terms of congruent dissolution of the K-feldspar, followed by precipitation of secondary silicate phases from a chemically saturated bulk solution. Other similar studies also support this type of process (Skorina and Allanore 2015; Su et al. 2015; Liu et al. 2018, 2019).

A study by Ciceri et al. (2017a) used ultrapotassic syenite, an intrusive igneous rock with a very high K-feldspar content, and poor in quartz. This material was subjected to 5 hours of alteration at 200 ${ }^{\circ} \mathrm{C}$ in a $\mathrm{Ca}(\mathrm{OH})_{2}$ solution. Based on chemical mapping and point analyses by electron probe microanalysis (EPMA) of the reacted powder (thin section-mounted), Ciceri et al. (2017a) propose that the original K-feldspar framework undergoes structural and chemical changes, and envision an $\mathrm{OH}^{-}$ mediated dissolution of the feldspar framework, accompanied by $\mathrm{Ca}-\mathrm{K}$ exchange. They state that "no single grain of K-feldspar preserved its original composition", and go on to describe an amorphous phase composed in part by "severely altered K-feldspar". This terminology is rather ambiguous, in particular as to whether such a phase, from a strict mineralogical-crystallographic point of view, can still be considered to be a true feldspar. The invoked Ca-K exchange, however, falls within the framework of traditional leached layer theory (Hellmann et al. 1990; Hellmann, 1999a,b, see also reviews and references in Hellmann et al. 2003, 2012, 2015). In this case, interdiffusion ultimately controls 285 preferential loss of $\mathrm{K}^{+}$from the structure and concomitant replacement by $\mathrm{Ca}^{2+}$ from the solution. The mechanism proposed by Ciceri et al. (2017a), however, can be questioned on a theoretical basis since it involves an ultraslow process (i.e., solid-state diffusion at $\left.200{ }^{\circ} \mathrm{C}\right)$ and an exchange couple $\left(\mathrm{K}^{+}\right.$and $\mathrm{Ca}^{2+}$ ) involving cations with significantly different ionic radii and valence. These authors also propose other possible mechanisms, including both mechanical and chemical, to explain $\mathrm{Ca}$ enrichment (see electronic supplementary file, Ciceri et al., 2017a). A final comment concerns their use of EPMA. Although this technique has superior detection limits compared to TEM-EDXS and EFTEM, it has a much larger beam footprint, which means that the spatial resolution is not optimally suited for determining the mechanism of dissolution. 


\section{$296 \quad 2.1$ Sample preparation and characterization}

297 Five different orthoclase samples were collected from 2 outcrops of a late Jurassic porphyritic felsite (an igneous rock with phenocrysts of orthoclase in a feldspathic matrix; also called orthophyre in older literature) near the cities of Xinghe and Chifeng, Inner Mongolia, China. The geological ages and emplacement histories of both felsites are very similar. These rocks were specifically chosen for their high alkali feldspar content, which in turn, makes them interesting candidates for hydrothermal Kextraction studies. This is the principal reason more common alkali feldspar-bearing rock types, like granite, were not chosen for this study.

The samples were dry crushed and ground in an agate mortar. Orthoclase grains were isolated by optical microscopy and heavy liquid separation, and then sieved, with the size fraction $<74 \mu \mathrm{m}$ being used for the alteration experiments. The specific surface area of each powder was determined by $\mathrm{N}_{2}-$ BET analysis. Representative secondary electron SEM images of grains comprising the starting materials (size fraction $<74 \mu \mathrm{m}$ ) for all 5 orthoclase samples are shown in the electronic Supplemental Material appendix: Figs. S1a-e. As revealed by the SEM images, the large grains have a blocky morphology, and show well developed cleavage planes. They do not appear to show any extensive fracturing as a result of comminution. A few of the large grains have $\mu \mathrm{m}$-sized internal void spaces, e.g., Fig. S1b. Based solely on an evaluation of the SEM images, these feldspars do not appear to have undergone any seritization or argillization reactions. The distribution of grain sizes is very heterogeneous, which is an expected finding for the preparation techniques used. No attempt was made to remove the abundant surface fines created during mechanical diminution of the grains.

It is widely recognized that feldspar microstructures play an important role in chemical weathering behavior and laboratory-measured dissolution rates. This has been documented for natural and experimentally weathered alkali feldspars in studies by, e.g., Lee and Parsons, 1995; Lee et al., 1998; see also references therein. The effect of microstructures on laboratory K-feldspar dissolution at alkaline hydrothermal conditions has been reported by, e.g., Locati et al., 2010, and more recently in a detailed study by Ciceri et al., 2017b. Dislocations and exsolution lamellae create localized regions of higher strain, which cause these crystallographically perturbed areas to dissolve significantly faster than the unstrained mineral structure. In this study, however, a detailed microstructural analysis of the raw alkali feldspar samples was not an immediate goal, as we were not attempting to measure the kinetics of dissolution, but rather the intrinsic mechanism of dissolution at the nanometer scale in interfacial areas that were not affected by dislocations or exsolution lamellae. 
Powder X-ray diffraction (XRD) confirmed that these 5 samples are orthoclase; the individual 328 diffraction patterns are shown in Fig. S2. In addition, XRD and Rietveld structure refinement were used 329 to determine semi-quantitative differences in $\mathrm{Al} / \mathrm{Si}$ ordering. Diffraction patterns were collected using a 330 Pananalytical X'Pert Pro diffractometer using CuK $\alpha$ radiation at $40 \mathrm{kV}$ and $40 \mathrm{~mA}$, with a $0.0167^{\circ}$ step 331 size over a $2 \theta$ range of $10-90^{\circ}$. Rietveld structure refinements of the XRD patterns reveal that differences in structural ordering (i.e., determined in terms of Al occupancy of $t_{1}$ tetrahedral site) between the samples can be considered to be minor- an example of a Rietveld refinement of unaltered orthoclase sample CHG-2- is shown in Fig. S3.

The mean chemical compositions and nominal chemical formulae of all 5 unaltered samples, determined by X-ray fluorescence, are given in Table 1. A standard sample preparation protocol was followed, and analyses were carried out using a Shimadzu 1500 XRF spectrometer. The compositional analyses are based on $8 \mathrm{O}$ atoms per formula unit, and the sum of the total cation charges (15.98-16.02) equals the total anion charge based on $\mathrm{O}$.

\subsection{Hydrothermal alteration}

The 5 orthoclase samples (Table 1) were reacted in separate experiments. This allowed us to measure the physical, structural and chemical changes that characterize typical post-reaction feldsparfluid interfaces at the nm-scale on grains from each sample. We deemed that this approach might be scientifically more interesting, as compared to running 5 replicates using just a single orthoclase sample. The experimental protocol that we used here has been adapted from standard methods that have been reported in other studies focused on the hydrothermal extraction of $\mathrm{K}$ from alkali feldspars in an alkaline medium (Su et al, 2015; Liu et al., 2015; Ciceri et al., 2017a). The use of $\mathrm{Ca}(\mathrm{OH})_{2}$ in this study as a base was deliberate so as to avoid the common ion effect that would be associated with $\mathrm{KOH}$, and to a lesser extent, $\mathrm{NaOH}$.

At the start of each experiment $1 \mathrm{~g}$ of orthoclase grains was mixed with $1 \mathrm{~g}$ of fresh $\mathrm{CaO}$ reagent, after which $10 \mathrm{ml}$ of ultrapure water were added. Given the hydrophilic nature of $\mathrm{CaO}$, it is assumed that an unknown amount of the oxide reacted with atmospheric humidity to yield $\mathrm{Ca}(\mathrm{OH})_{2}$ during the setup of each experiment. The $\mathrm{pH}_{\left(25^{\circ} \mathrm{C}\right)}$ of the starting solution before the orthoclase was added was 12.3-12.5. The admixture was stirred for 5 minutes before being sealed in a $100 \mathrm{~mL}$ stainless steel autoclave with a teflon liner. No degassing of the solution was carried out- therefore a non-quantified amount of dissolved $\mathrm{CO}_{2}$ was a component of the aqueous solution. The sealed autoclave was placed into an oven pre-heated to $190{ }^{\circ} \mathrm{C}$ and left for $24 \mathrm{~h}$ at this temperature. The autoclave was then cooled down to 
drive off any remaining fluid. The retrieved solid cake was then reground by mortar and pestle to a size

361 fraction $<74 \mu \mathrm{m}$. The reground, altered material (hereafter 'hydrothermal product') served as the basis 362 for further solid-state analyses. The entire hydrothermal alteration process and the associated analyses 363 are schematically shown in Fig. 1. We note that one sample was reacted in duplicate, producing sample CSY-1C-a. The experimental protocol was identical, except that the second heating step at $105{ }^{\circ} \mathrm{C}$ was omitted since no liquid remained after the primary hydrothermal reaction step at $190{ }^{\circ} \mathrm{C}$.

\subsection{BET and XRD of reaction products}

The specific surface areas of the fresh and altered powders $(<74 \mu \mathrm{m}$ size fraction) were measured by $\mathrm{N}_{2}$-BET analyses using a Belsorp-Max volumetric gas sorption instrument. The samples were first outgassed at $150{ }^{\circ} \mathrm{C}$ for $6 \mathrm{~h}$ under vacuum. The specific surface areas of powdered samples are based on the Brunauer-Emmet-Teller (BET) equation $\left(0.05 \leq \mathrm{P} / \mathrm{P}_{0} \leq 0.2\right)$ using $16.2 \AA^{2}$ as the crosssectional area of $\mathrm{N}_{2}$. The average surface area of the 4 starting materials is $3.4 \mathrm{~m}^{2} \mathrm{~g}^{-1}$, while the altered average is $12.6 \mathrm{~m}^{2} \mathrm{~g}^{-1}$ (Table 2). Thus, the average surface area increased by half an order of magnitude due to alteration. As shown further on, the precipitation of an amalgam of very small secondary phases explains this finding; this has also been confirmed in other similar studies. For example, using a particle size distribution analysis of unreacted and reacted materials, Ciceri et al. (2017a- Fig. 6) noted a significant shift to smaller particle sizes upon alteration, reflected both in terms of particle volume \% and particle number $\%$.

Although the identification and detailed characterization of the crystalline authigenic phases produced in the experiments were not the goal of this study, their presence cannot be neglected since they occur within the interfacial region of the reacted feldspar grains, which was the main region of interest. For this reason, we measured K concentrations associated with these secondary phases, as this allowed us to qualitatively follow the fate of released $\mathrm{K}$ from the orthoclase. Below we describe the standard X-ray powder diffraction (XRD) techniques that were employed to identify the crystalline mineral phases present in the hydrothermal product- these are discussed further on in Section 3.1

The reacted samples were ground using a McCrone micronising mill to produce a size fraction < $1 \mu \mathrm{m}$. XRD analyses were run using a Bruker D5000 powder diffractometer equipped with a SolX Si (Li) solid state detector (Baltic Scientific Instruments) using $\mathrm{CuK \alpha}$ radiation at $40 \mathrm{kV}$ and $40 \mathrm{~mA}$. Diffraction intensities were recorded at $0.026^{\circ} 2 \theta$-step intervals from 5 to $90^{\circ}(5 \mathrm{~s}$ counting time per step) for bulk mineralogy determination. The identification of secondary mineral products by X-ray 
diffraction file database for phases that commonly occur when silicates are chemically altered at alkaline 393 hydrothermal conditions.

394 The Rietveld refinement method was then used to quantify the phases in terms of mass \% (we prefer this term vs. weight $\%$ ). The generally accepted quantification limit is 1 mass $\%$, although this can be lower $(\sim 0.5)$ for phases with non-convoluted peaks. We used the code Profex (Döbelin and Kleeberg, 2015), which is a graphical user interface for Rietveld refinement of powder XRD data using the program BGMN (Bergmann, 2005). In general, when the Rietveld refinement indicated that a selected phase was present at $<1$ mass $\%$, this phase was then purposely deleted from further refinements- this served to restrict the number of phases used for fitting.

The percentage of amorphous component in one sample (CSY-1C-a) was determined using a standard method, Rietveld quantitative amorphous content analysis (de la Torre et al., 2001). This method is based on measuring the XRD pattern of the hydrothermal product before and after the addition of a known, precise quantity of an internal crystalline standard. While many standards can be employed, we used pure corundum $\left(\mathrm{Al}_{2} \mathrm{O}_{3}\right.$; Alfa Aesar, \#42573 $\alpha$ phase). The sample-internal standard mixture, containing exactly 30.4 mass $\% \mathrm{Al}_{2} \mathrm{O}_{3}$, was mixed and homogenized in the presence of ethanol using a McCrone mill. As already noted above, sample CSY-1C-a underwent the same hydrothermal alteration as CSY-1C, except that the heat treatment step at $105^{\circ} \mathrm{C}$ was omitted. In general, XRD cannot distinguish between a discrete amorphous phase and nano-crystalline or poorly crystalline material. Therefore, the amorphous material quantified by XRD-Rietveld refinement in this study includes discreet amorphous phases, as well as nanocrystalline and poorly crystalline material dispersed among the secondary phases comprising the hydrothermal product.

\subsection{Resin impregnation}

After hydrothermal alteration the reacted orthoclase powders were embedded in a liquid C-based epoxy resin (Struers) that was allowed to harden in a mold. The dried mounts were then polished on SiC-coated disks in the presence of ultrapure water, finishing with a polish using a $5.0-\mu \mathrm{m}$ granulometry. This methodology provided us with embedded cross sections of randomly oriented mineral grains and their alteration products. Even though brief contact with ultrapure water was unavoidable during polishing, the resin impregnated the secondary products, thereby protecting them from reaction with water. We also note that despite polishing, not all primary feldspar grains were flush with the surfaces of the mounts. Numerous grains remained slightly below the polished surfaces, which allowed secondary precipitated phases to be preserved in their native configuration on the grain surfaces. 
424 For example, in Fig. 2b, note the presence of 'free standing' scalenohedral calcite crystals on top of the 425 orthoclase grain. The lack of any visible signs of chemical corrosion, in particular with respect to soluble 426 secondary phases like calcite, support the premise that the protocol we used was not deleterious. The remaining primary K-feldspar grains also did not display any evidence of additional dissolution (e.g. 428 etch pits) from the polishing step. This is perhaps expected, as feldspars in general are quite robust 429 minerals, and are not very reactive in pure water at ambient temperature. All samples were carbon sputter coated before analysis by FESEM (C-coat thickness was a few tens of nm).

\subsection{FESEM}

Even though the main analytical technique for this study was TEM, we also used scanning electron microscopy (SEM) to obtain images at the $\mu \mathrm{m}$-scale. This allowed us to obtain an overall largescale picture of the nature of the reacted feldspar grains. The secondary precipitates form a 'reaction rim' around each grain. Because the objective of our study was a detailed investigation of the orthoclasefluid interface, we deemed it logical to also include these secondary precipitates in our measurements and observations at both the $\mu \mathrm{m}$ and nm scales.

The polished mounts from all 5 experiments were extensively investigated. Individual orthoclase grains and their rims of hydrothermally altered products were imaged with a high-resolution field emission scanning electron microscope (FESEM): Zeiss Ultra Plus (PISA Facility- GFZ Potsdam). The acceleration voltage was $20 \mathrm{kV}$, with a $120-\mu \mathrm{m}$ aperture. The use of standard detectors allowed imaging of backscattered (BSE) and secondary electrons (SE). Chemical maps and spectra were measured by energy dispersive X-ray spectroscopy (EDXS). The FESEM is equipped with a Thermo Fisher Scientific UltraDry SDD EDX detector. The chemical spectra are based on standard $K$-lines for all elements of interest ( $\mathrm{Si}, \mathrm{Al}, \mathrm{O}, \mathrm{K}, \mathrm{Na}, \mathrm{Ca}, \mathrm{C})$. We examined the orthoclase samples by FESEM imagery, EDXS spot analyses (ZAF-corrected), and chemical maps (based on raw net counts with background subtraction). The ZAF-corrected elemental counts can be considered to be semi-quantitative. Analyses of carbon in particular are problematical because of the unavoidable contributions from the epoxy resin to the total $\mathrm{C}$ signal, and to a much lesser extent, from the carbon sputter coating. This resulted in probable overestimations of $\mathrm{C}$ in carbon-bearing secondary phases, in particular calcite that precipitated within the amalgam of secondary phases.

\subsection{FIB}

Using focused ion beam (FIB) preparation, electron transparent ultra-thin sections were extracted 
457 (CSY-1C and CSY-3C) were investigated at the nanometer-scale by TEM. With respect to sample CSY-

458 1C, two FIB lamellae were fabricated at different locations on the same grain that was previously 459 observed by FESEM. For CSY-3C, one FIB lamella was produced from a grain that had also been 460 investigated by FESEM. The FIB thin sections were prepared with a FEI Helios G4 UC Dual Beam 461 (SEM-FIB) instrument housed at GFZ. In general, the FIB lamellae were milled from vertical cuts on 462 polished grain surfaces. For each lamella, a large primary orthoclase grain was selected, and the milling 463 location was chosen so as to include the interface between the grain and the adjacent lateral alteration 464 rind composed of secondary precipitates.

465 The FIB protocol can be very briefly summarized as follows. After the deposition of a Pt strap at 466 the chosen area on a polished grain surface, milling with a Ga beam proceeds at an accelerating voltage 467 of $30 \mathrm{kV}$ and a beam current of $47 \mathrm{nA}$, which is later on decreased to $9 \mathrm{nA}$. After the lamella is cut free 468 from the matrix, it is transferred in situ to a $\mathrm{Cu}$ TEM grid, where it is welded to one of the grid posts. 469 Once firmly attached, additional thinning takes place with a $30 \mathrm{kV}, 41 \mathrm{pA}$ Ga beam. Progressive 470 thinning is achieved by steadily decreasing the voltage, such that in the final step, the voltage is reduced 471 to $5 \mathrm{kV}$. The final step ensures that much of the lateral-edge amorphous material created during milling 472 is effectively removed. The final result is an electron transparent ultrathin section with typical 473 dimensions of 15-20 $\mu \mathrm{m}$ (length) x 5-10 $\mu \mathrm{m}$ (height) x 150-200 nm (thickness). A more detailed 474 description of the procedure that we used can be found in Wirth (2009). Even though not available to us 475 at the time, as a final step it is generally advisable to remove implanted Ga from FIB lamellae using an 476 Ar ion nano-milling technique (see, e.g., Supplemental Information in Leonard and Hellmann, 2017).

\subsubsection{TEM: FEI Tecnai}

The vast majority of the transmission electron microscopy work was carried out on a FEI Tecnai G2 F20 X-twin FEG TEM operating at $200 \mathrm{kV}$ (GFZ). This TEM is equipped with standard BF (bright field), DF (dark field) and STEM-HAADF (scanning TEM-high angle annular dark field) detectors, a post-column Gatan Tridiem energy analyzer for EFTEM (energy filtered TEM) and EELS (electron energy-loss spectroscopy), and an EDAX energy dispersive X-ray spectrometer equipped with a Si-Li detector. We did not attempt to determine complete chemical compositions at specific locations by EDXS spot analyses- this normally requires separate analysis of external standards. Instead, we scanned the electron beam within a pre-selected area (whose size was dependent on the object being analyzed), and then quantified the chemistry using three elemental atomic ratios: $\mathrm{Al} / \mathrm{Si}, \mathrm{K} / \mathrm{Si}$, and $\mathrm{Ca} / \mathrm{Si}$ (Table 3). As a first approximation, we assumed that the 'thin-film' criterion holds, which means that X-ray 
490 Lorimer, 1975), based on $k_{\mathrm{AB}}$ factors, was used to determine atom \% of $\mathrm{Al}, \mathrm{Si}, \mathrm{K}$, and Ca, allowing $491 \mathrm{Al} / \mathrm{Si}, \mathrm{K} / \mathrm{Si}$, and $\mathrm{Ca} / \mathrm{Si}$ ratios to be determined. For these elements, the built-in EDAX software 492 standardless $k_{\mathrm{AB}}$ factors were considered to be sufficiently accurate; however, this was not true for O. 493 Due to Ga implantation into the lamella during the FIB fabrication process, we did not attempt to 494 quantify $\mathrm{Na}$ by deconvoluting overlapping $\mathrm{Ga} L$ and $\mathrm{Na} K$ peaks in EDXS spectra.

495 In several instances, we recorded selected area EELS spectra of the C $K$ and the Ca $L_{2,3}$ edges (in 496 EELS spectrum mode) of prominent bands that parallel the orthoclase interface. In each case, the EELS 497 background was fit with a standard polynomial function and subtracted from the spectrum using a 498 standard method that is a part of the Gatan ${ }^{\circledR}$ GMS software package. In addition to EELS, we also used 499 EFTEM to provide relatively high spatial resolution chemical maps of certain interfacial regions. 500 EFTEM is an advanced method for obtaining chemical maps of light elements with nanometer-scale 501 spatial resolution (Grogger et al., 2003). The detection limit is generally in the parts per thousand range. 502 The distribution of a chosen element can be portrayed either with a 2-window (jump ratio) or a 3503 window (chemical map) image. To produce a jump ratio image of a certain element, an appropriate 504 ionization edge is chosen, and two energy-filtered images are made, one before the edge, and one after. 505 The post ionization edge image is then divided by the pre-edge image, and the result is a jump ratio 506 element distribution map. The 3-window map approach is based on obtaining two pre-edge images and 507 one post edge image. The spectral background curve is then calculated, such that the area under the post508 edge peak can be determined- this difference is the net core-loss signal, which is proportional to the 509 concentration of the element.

\subsubsection{TEM: FEI Themis Titan}

The second TEM instrument that we used is a recent aberration-corrected FEI Themis Titan that was operated at $200 \mathrm{kV}$ (Minatec, Grenoble, France). This TEM, with its four Bruker EDX detectors (30 $\mathrm{mm}^{2} \mathrm{x} 4 ; 0.68$ radians), allows for very rapid acquisition of chemical maps with much lower beam currents compared to conventional TEM instruments (e.g., Tecnai, GFZ). We typically used beam currents of $200 \mathrm{pA}$. Because of these technical advantages, this TEM instrument was principally used to obtain high-resolution STEM and EDXS chemical maps of the interfacial regions. Measurements of certain elements, such as $\mathrm{K}$ and $\mathrm{Na}$, on the same feldspar interfacial areas with both TEM instruments revealed the inherent advantages of the FEI Themis. It has already been reported that the measurement of accurate $\mathrm{K}$ and $\mathrm{Na}$ levels in silicates by analytical TEM is difficult due their mobility under an electron beam (van der Pluijm et al., 1988). This phenomenon is particularly prevalent in thinner areas 
523 orientation have been shown to play important roles. In addition to these factors, the position of the 524 detector with regard to a wedge-shaped sample (most FIB thin foils are in fact wedge-shaped in cross 525 section) directly affects the X-ray absorption distance (Williams and Carter, 2009), which can also 526 influence the EDXS measurements.

527 The EDXS chemical maps were generated by X-ray intensities measured by the 4 EDX detectors, 528 and are based on measured elemental $K$ edge intensities that have not been corrected. Thus, EDXS maps show relative concentrations for each element. On the other hand, quantitative chemical analyses of specific areas were measured with just one of the four detectors, as we selected the detector that offered the best detector-sample geometry in order to reduce as much as possible X-ray absorption effects. Moreover, specific-area chemical compositions have been corrected for X-ray absorption effects according to the iterative $\zeta$ (zeta) method described by Watanabe and Williams (Williams and Carter, 2009; Watanabe and Williams, 2006) and implemented using a specific code (Robin, 2017). This method largely surpasses the Cliff-Lorimer (i.e. $k$ factor correction) method (Cliff and Lorimer, 1975) and provides a relatively accurate quantification of the chemical composition.

\section{Results}

\subsection{X-ray powder diffraction and Rietveld refinements.}

X-ray powder diffraction (XRD) of the five original hydrothermally altered orthoclase samples was used to identify the major ( $>0.5$ mass \%) crystalline phases, followed by Rietveld refinements (Figs. S4a-e) to estimate the approximate mass percentages present. One additional sample, the replicate CSY-1C-a, was similarly analyzed (Fig. S4f). All six diffraction diagrams show a strong central peak (calcite), in conjunction with other distinct smaller peaks and numerous very weak peaks. Fitted backgrounds (Figs. S4a-e) reveal a smooth bump between $20-50^{\circ}(\mathrm{Cu} K 2 \theta$ ), suggesting roughly similar amounts of amorphous material in all 5 samples. The replicate sample (CSY-1C-a, Fig. S4f) was analyzed specifically for its amorphous content, which was determined to be $\sim 16 \%$. This compares to amorphous components of $18 \%$ (Ciceri et al., 2017a) and 5-30\% (Liu et al., 2019) reported in other studies devoted to alkaline hydrothermal alteration of K-feldspars.

XRD confirms that the conversion of orthoclase did not go to completion in the hydrothermal runs, as the fraction of unaltered orthoclase is significant, 11-21\%. No other feldspar phases were found (> 5520.5 mass \%), in particular potential secondary authigenic feldspars. In all experiments, the dominant 553 secondary phase that formed is calcite $\left(\mathrm{CaCO}_{3}\right), 35-50 \%$. A minor amount of the polymorph vaterite 554 formed in only one experiment, CSY-1C-a (1.5\%). Since the orthoclase samples contain only trace 
amounts of $\mathrm{Ca}$ (Table 1), calcite is rather a byproduct of aqueous calcium cations reacting with dissolved atmospheric $\mathrm{CO}_{2}$ in the $\mathrm{CaO}-\mathrm{H}_{2} \mathrm{O}$ alkaline solvent, and then precipitating during the course of the experiments.

After calcite, the next most abundant secondary phases are all silicate minerals containing variable amounts of $\mathrm{Ca}$ and $\mathrm{Al}$ oxides, and including $\mathrm{OH}$ and/or $\mathrm{H}_{2} \mathrm{O}$. Crystalline phases with these chemical components also commonly form during cement hydration experiments, which is logical, as alkaline conditions are also prevalent. We thus make use of the CASH and CSH nomenclature from the cement literature to designate in a generalized manner non-stoichiometric calcium $(\underline{\mathrm{CaO}})$-aluminate $\left(\underline{\mathrm{Al}}{ }_{2} \mathrm{O}_{3}\right)$ silicate $\left(\underline{\mathrm{SiO}}_{2}\right)$ hydrate $\left(\mathrm{O} \underline{\mathrm{H}}, \mathrm{H}_{2} \mathrm{O}\right)$ mineral phases. As described later on, the secondary products that formed are for the most part an amalgam of intergrown and superposed phases, and thus we simply refer to them together as $\mathrm{CASH}, \mathrm{CSH}$, and/or carbonate.

The sum of CASH and CSH phases make up between 43.0 and $54.3 \%$ of the final run products, with one outlier (sample CHG-12C) at only $28.4 \%$. The two replicate experiments (CSY-1C and CSY$1 \mathrm{C}$-a) have very similar values, 52.9 and $52.8 \%$. Equation 2 describes a possible macroscopic reaction for the formation of these secondary silicate phases. The two most prominent CASH minerals (18-24 \%) are the cubic phases hibschite and katoite. Both are hydrated members of the (hydro)grossular garnet series (see note $\mathrm{S} 1$ ): $\mathrm{Ca}_{3} \mathrm{Al}_{2}\left(\mathrm{SiO}_{4}\right)_{3-\mathrm{x}}(\mathrm{OH})_{4 \mathrm{x}}$ : grossular, $x=0$; hibschite, $x=0.2-1.5$; katoite, $x=1.5-3.0$ (with increasing hydration $\mathrm{OH}$ substitutes for $\mathrm{SiO}_{4}$ groups). The dominant $\mathrm{CSH}$ mineral that precipitated is tobermorite $11 \AA(8-31 \%)$, which crystallizes in the orthorhombic system with a fibrous or bladed habit: $\mathrm{Ca}_{5} \mathrm{Si}_{6} \mathrm{O}_{16}(\mathrm{OH})_{2} \cdot 4 \mathrm{H}_{2} \mathrm{O}$. Coupled substitution of $\left[\mathrm{Al}^{3+}+\mathrm{Na}^{+}\right]$for $\mathrm{Si}^{4+}$ can result in an Al-substituted $11 \AA$ tobermorite. Fitting the tobermorite peak proved to be the most challenging aspect of the Rietveld refinements, and was achieved with an adjustable mixture of micro- and nano-crystalline crystals. Using the Bragg equation we verified that the $d$-spacing was indeed $11 \AA$ for this phase.

During the Rietveld refinements, in order to constrain our results to the major secondary phases present, we purposely excluded phases with concentrations less than 1 mass \%. However, this discrimination protocol doesn't imply that these phases did not form, but simply that they precipitated very sparingly, and it was decided not to quantify them further. Thus, the crystalline phases vaterite $\left(\mathrm{CaCO}_{3}\right)$, bütschliite $\left(\mathrm{K}_{2} \mathrm{Ca}\left(\mathrm{CO}_{3}\right)_{2}\right)$, $\alpha$-dicalcium silicate hydrate $\left(\mathrm{Ca}_{2} \mathrm{SiO}_{3}(\mathrm{OH})_{2}\right)$, kalsilite $\left(\mathrm{KAlSiO}_{4}\right)$, hydroxycancrinite $\left(\mathrm{Na}_{8} \mathrm{Al}_{6} \mathrm{Si}_{6} \mathrm{O}_{24}(\mathrm{OH})_{1.4}\left(\mathrm{CO}_{3}\right)_{0.3} \cdot 6.35\left(\mathrm{H}_{2} \mathrm{O}\right)\right.$, belite $\left(\mathrm{Ca}_{2} \mathrm{SiO}_{4}\right)$, and panunzite $\left((\mathrm{K}, \mathrm{Na}) \mathrm{AlSiO}_{4}\right)$ were excluded from our final results (excepting vaterite in CSY-1C-a). Figure S5 shows the partitioning of the hydrothermal product from the 6 alteration experiments in terms of remaining orthoclase and the major secondary crystalline phases. 
In a broad sense, the secondary phases determined in our study are similar to those in other studies that have focused on alkaline hydrothermal extraction of $\mathrm{K}$ from alkali feldspars. It is important to note that the exact assemblage of secondary mineral and amorphous phases depends on many variables, and can be a function of different starting materials (alkali feldspar-rich rock vs. alkali feldspar), different polymorphs of alkali feldspar, differences in internal microstructures and $\mathrm{Al} / \mathrm{Si}$ ordering, solvents with different chemical compositions, i.e., $\mathrm{NaOH}, \mathrm{KOH}, \mathrm{Ca}(\mathrm{OH})_{2}$, and differences in temperature, run times, water/rock ratios, as well as other experimental variables. Overall, hydrogrossular and tobermorite have been reported to be generally present in other studies, but their proportions are quite variable (Liu et al., 2015, 2018, 2019; Ciceri et al., 2017a). Abundant calcite was also measured in studies by Liu et al., 2015, 2018, 2019. Phases such as $\alpha$-dicalcium silicate hydrate and panunzite have been documented, but in higher proportions than in our study (Ciceri et al., 2017a; Liu et al., 2018, 2019). Moreover, some studies have found a much different assemblage of secondary minerals (e.g., Su et al., 2015), dominated by kalsilite and hydroxycancrinite, for example. One study has listed as the dominant hydrothermal product phase 'altered' K-feldspar (66.5 \%, Fig. 2, Ciceri et al., 2017a), but as already discussed, the meaning of what this 'phase' actually represents is not clear.

\subsection{Micrometer-scale images by FESEM and EDXS.}

Numerous altered orthoclase grains from all 5 samples were examined in polished cross sections at various scales by field emission scanning electron microscopy (FESEM) and energy dispersive X-ray spectroscopy (EDXS). Here we describe one representative sample: CSY-1C. Figure 2a is a secondary electron (SE) image of a large primary grain of orthoclase characterized by a prominent $1-2 \mu \mathrm{m}$-thick halo of secondary precipitated phases. This type of morphology characterizes orthoclase grains in all samples. The rind of secondary phases (Fig. 2b, location 1) contains both fine-grained material and larger bladed precipitates (probably tobermorite, with some calcite; calcite also formed individual $\mu \mathrm{m}$ sized scalenohedral and rhombohedral crystals on the polished surface). The three globular entities above the large grain (nos. 2, 3, 4) are estimated to be an amalgam of CASH $+\mathrm{CSH}$ phases and calcite, with variable amounts of small orthoclase grains.

The EDXS chemical maps in Fig. 3a-f show the relative concentrations of $\mathrm{K}, \mathrm{Ca}, \mathrm{Si}, \mathrm{Al}, \mathrm{C}$, and $\mathrm{O}$ at the same grain location (Fig. 2b). Compared to the uniformly high concentration of $\mathrm{K}$ in the large orthoclase grain, $\mathrm{K}$ is present at significantly lower levels in the alteration halo (rind, no. 1) and in the large globular entity (no. 4), but at relatively higher levels in entity 2, and particular in entity 3. Potassium at locations 1-4 is associated primarily with secondary phases, and to a lesser degree with very small orthoclase grains. The rind (area 1) is particularly enriched in $\mathrm{Ca}$, but nonetheless, also 
contains $\mathrm{Si}, \mathrm{Al}$ and $\mathrm{O}$ at lesser concentrations. It most likely consists of a mixture of calcite and $\mathrm{CASH}+$

$621 \mathrm{CSH}$ phases. Entities 2 and 3 show a relatively good correlation among K, Ca, Si and Al. In contrast, 622 entity 4 is different: enrichment in $\mathrm{Ca}$ and $\mathrm{O}$, low $\mathrm{Si}$, and near absence in $\mathrm{Al}$. Aside from a notable $\mathrm{C}$ presence in the resin, there are a few $\mathrm{C}$ hotspots present in the rind (no. 1), with lesser amounts visible in

624 entities 3 and 4, and the periphery of entity 2 (but lacking in core). The partitioning of the total carbon 625 signal, while heavily weighted to the resin, is of course also attributable to $\mathrm{CaCO}_{3}$ (calcite) precipitates. 626 Even though one would expect a good spatial correspondence between $\mathrm{C}$ and $\mathrm{Ca}$, this is not always the 627 case, e.g., in the rind (1). Binary elemental overlay maps (Figs. S6a-c) reinforce the conclusions drawn 628 from the single element maps.

\subsection{Nanometer-scale measurements of orthoclase interface by TEM.}

\subsubsection{Chemistry and structure of feldspar and precipitates}

Figure 4a is a HAADF-STEM image of an orthoclase grain (CSY-1C) prepared in cross section by focused ion beam milling (FIB). The white arrows indicate a sharp and distinct interface between the orthoclase and the enveloping alteration halo of secondary precipitates. The precipitates display various types of morphologies, including a single large grain, granular aggregates, bladed crystals, and a probable amorphous phase characterized by a large $(\sim 400 \mathrm{~nm})$ pore, abutting the orthoclase grain. The majority of the material in the alteration halo is slightly darker in tone, indicating lesser mass-density compared to the orthoclase. The 8 rectangles indicate the areas that were analyzed by EDXS (Table 3).

Areas 1 and 2 correspond to the nominal composition of orthoclase, with the expected atomic ratios; e.g., $\mathrm{K} / \mathrm{Si}=0.24$ and 0.23 at locations 1 and 2 , respectively. In other grain interior locations of this sample, similar $\mathrm{K} / \mathrm{Si}$ values were recorded, resulting in an average nominal orthoclase $\mathrm{K} / \mathrm{Si}$ ratio of 0.24-0.25. Curiously, at area 3, which is at the edge of the orthoclase grain, the K/Si ratio is only 0.17 , which is significantly lower than the nominal value, and yet the measurement was taken fully within orthoclase. This was found to be the case with many other (but not all) EDXS measurements taken at grain edges, where in some cases, $\mathrm{K} / \mathrm{Si}$ values are even lower. As detailed further on, this effect is not due to chemical alteration and leaching of $\mathrm{K}$ from the orthoclase, but is rather an analytical artifact. The $\mathrm{Ca} / \mathrm{Si}$ ratios measured at areas 1-3 reveal that at the scale of the analyses and the analytical resolution of these particular TEM-EDXS measurements, there is no evidence for $\mathrm{Ca}$ entering into the orthoclase structure. Based on morphology and chemical composition, areas 6 and 8 most likely correspond to an amalgam of hydrogrossular and tobermorite phases. The phases represented by areas 4, 5, and 7 are difficult to identify, but based on chemistry and morphology, 7 may be Al-tobermorite. The large pore 
653 discreet phase with low mass-density that directly abuts the orthoclase edge. Area 5 has elevated K/Si 654 and $\mathrm{Al} / \mathrm{Si}$ ratios, and a $\mathrm{Ca} / \mathrm{Si}$ ratio indicating minor $\mathrm{Ca}$ enrichment- this phase is not identifiable, 655 however. Notwithstanding the tenuous identification of the secondary phases, they all contain K, and in 656 one case (area 5), a K/Si value of 0.30 is measured (i.e., compare to nominal unaltered orthoclase value 657 of 0.22$)$.

658 The HAADF-STEM image in Fig. 4b shows a cross-sectional view of a primary orthoclase grain 659 (CSY-3C), also with a sharp boundary between orthoclase and secondary precipitates. Four areas were 660 measured by EDXS analyses (Table 3). The chemistry of area 9 has elevated K levels, and may 661 represent a mixture of Al-tobermorite with other phases (i.e. measured $\mathrm{Ca} / \mathrm{Si}=1.11$ ). Area 10 is likely a 662 resin-filled pore primarily composed of $\mathrm{C}$ and $\mathrm{O}$, but $\mathrm{K}, \mathrm{Ca}, \mathrm{Al}, \mathrm{Si}$ are measurable in the spectra, which 663 is possibly attributable to the presence of nano-precipitates that are not visible in the image. The 664 presence of a $60-\mathrm{nm}$ thick continuous band of precipitate in close proximity to the orthoclase sets this 665 image apart from previous examples. The EDXS spectrum reveals (area 11) a very high Ca 666 concentration, significant $\mathrm{C}$, the near absence of $\mathrm{Si}$ and $\mathrm{Al}$, and elevated $\mathrm{K}$ - it is therefore most likely 667 calcite, but in the presence of a minor phase(s) containing $\mathrm{K}$. We can at this point only speculate that the 668 elevated $\mathrm{K}$ concentrations might be due to the presence of K-bearing nanoparticles, or possibly even a 669 K-rich carbonate phase, such as $\mathrm{K}_{2} \mathrm{CO}_{3}$ (formed via one possible reaction: $\mathrm{KOH}+\mathrm{CO}_{2}$ aq), or even 670 bütschliite, $\mathrm{K}_{2} \mathrm{Ca}\left(\mathrm{CO}_{3}\right)_{2}$. The chemical analyses at area 12 correspond to the composition of unaltered 671 orthoclase, with $\mathrm{K} / \mathrm{Si}=0.23$. Calcium is present at the EDXS detection limit, $\mathrm{Ca} / \mathrm{Si}=0.0011$.

A second HAADF-STEM image of the same interface (CSY-3C), but at a new location, is shown in 673 Fig. 4c (EDXS chemistry of areas 13-16, see Table 3). The band of calcite, while not well defined, is 674 still present, with $\mathrm{K} / \mathrm{Si}=0.09$ (area 14). As already discussed, the measured $\mathrm{K}$ and Si most likely 675 indicate the presence of minor amounts of silicate particles. Here the band is separated from the 676 orthoclase by a precipitate (area 13) with pores having dimensions of several tens of nm (pores appear as 677 black entities). The presence of numerous pores and the general morphology, the low mass-density, and 678 a chemical composition inconsistent with any of the phases identified by XRD (Fig. 2), suggest that this 679 may be an amorphous phase, perhaps similar to the one described in Fig. 4a. Areas 15 and 16 have 680 relatively similar $\mathrm{Al} / \mathrm{Si}$ and $\mathrm{Ca} / \mathrm{Si}$ chemistries, and may be an amalgam of crystalline and amorphous 681 material. Their K/Si ratios are very different, however, which at area 15 is 0.60 . This elevated ratio 682 cannot be attributed to a very low concentration of $\mathrm{Si}$, given that the Si counts are the same in area 16. 683 Whether there is any calcite in this region is not known. Figure 4c also shows the omnipresence of 684 white-colored nm-sized precipitates. Further along the same interface, 4 more areas were characterized 685 (areas 17-20, Table 3; TEM image in Fig. S7). Area 17, which is within another thin band of (possibly 
amorphous) precipitate in close proximity to the orthoclase, also has an elevated $\mathrm{K} / \mathrm{Si}$ ratio $=0.19$.

687 Taken together (Figs. 4a-c, Fig. S7), these findings reveal that certain secondary phases, both crystalline 688 and amorphous, are associated with significant levels of $\mathrm{K}$.

\subsubsection{Calcite in interfacial region}

691

692

693

694

695

696

697

698

699

700

701

702

703

704

705

706

707

708

709

710

711

712

713

714

715

716

717

The intermediate resolution bright field (BF) TEM image in Fig. 5a (CSY-3C) displays another example of a continuous $\sim 60 \mathrm{~nm}$-wide linear band of calcite that runs parallel to the orthoclase interface. In BF imaging, calcite is easily distinguished by its mottled appearance. The calcite band does not touch the orthoclase, but rather occurs within an aggregate of precipitated phases characterized by bladed crystals (likely tobermorite), a large granular globule (demarcated by 3 open-ended arrows), and a finegrained matrix between the bladed crystals. The matrix itself contains nm-sized dark grains, which probably correspond to the white grains observed in Fig. 4c. The presence of numerous bubbles (e.g., white globules, next to scale bar) throughout the precipitate most probably indicate trapped water, which would imply that the precipitation rind is significantly hydrated. The external edge of the orthoclase grain appears to end abruptly at a continuous parallel band that may be amorphous ( 2 white arrows, dashed tails).

To confirm the presence of calcite in the aforementioned bands (Figs. 4b,c, 5a), we recorded selected area EELS spectra of the $\mathrm{C} K$ and the $\mathrm{Ca} L_{2,3}$ edges (in EELS spectrum mode). The deconvolved, background subtracted spectrum (Fig. 5b) of the band delimited by the solid white arrows in Fig. 5a confirms that this is calcite. The spectra show two distinct $\mathrm{C} K$-edges, one at $289 \mathrm{eV}$ and the other at $300 \mathrm{eV}$. These two edges are characteristic for calcium carbonates, and represent two different electronic transitions, the first $1 \mathrm{~s} / \pi^{*}(\mathrm{C}=\mathrm{O})$ and the second $1 \mathrm{~s} / \sigma^{*}(\mathrm{C}-\mathrm{O})$ (Martin et al., 1996). The peak maxima for the $\mathrm{Ca} L_{2,3}$ peak are at 348 and $351 \mathrm{eV}$. The $\mathrm{C}$ and $\mathrm{Ca}$ spectra provide proof that the uniform and continuous bands, as evidenced in Figs. 4b,c and 5a, are crystalline Ca-carbonates. Based on the EELS spectra alone, it is not possible to distinguish between the two polymorphs calcite and vaterite, but the Rietveld refinement for this sample favor the former.

\subsubsection{Does Ca enter the orthoclase structure?}

To determine the chemical stability of the original orthoclase structure with respect to the Ca-rich solvent during the alteration process, we investigated whether there was evidence for $\mathrm{Ca}$ entering the orthoclase structure by interdiffusion, or alternatively, by the replacement of the original orthoclase with a Ca-rich secondary phase, such as anorthite, the Ca-end member plagioclase feldspar $\left(\mathrm{CaAl}_{2} \mathrm{Si}_{2} \mathrm{O}_{8}\right)$. To 
718 explore this question we used energy filtered TEM (EFTEM) imaging, a powerful and yet under-utilized 719 TEM method in mineralogy and geochemistry. Figures 6a, b are complementary images, and both show 720 the same well-defined interface (white arrows) between orthoclase (CSY-1C) and secondary 721 precipitates. The first is a BF TEM image- it shows a complex amalgam of secondary precipitates, 722 including bladed crystals, a fine-grained grey groundmass, calcite (?), nanometer-sized particles, and 723 what appear to be extremely small globules (light grey to white, indicating possible evidence for water). 724 The precipitates terminate abruptly at the orthoclase interface.

725 Figure $6 \mathrm{~b}$ is the corresponding $\mathrm{Ca} L_{2,3}$ EFTEM 3-window chemical map at slightly lower 726 magnification. The widths of the 3 windows (all equal in energy) and the polynomial function used to fit 727 the spectral background were calculated with Gatan Microscopy Suite (GMS) software. In the Ca map, 728 white regions correspond to elevated Ca concentrations (secondary precipitates), and conversely, black 729 regions indicate a lack of $\mathrm{Ca}$, such as is the case for the Ca-devoid orthoclase structure and resin. Note 730 that the precipitates do not have a uniform white color, which indicates variable Ca levels and/or 731 differences in thickness. Most importantly, the chemical gradient of $\mathrm{Ca}$ at the orthoclase-precipitate 732 interface is quite sharp and resembles a step-function change. Therefore, at the spatial/energy resolution 733 of this EFTEM image, there is no evidence for the incorporation of $\mathrm{Ca}$ into the orthoclase structure, 734 either by mineral-mineral replacement or by interdiffusion.

735 The interested reader may question why a potassium EFTEM chemical map is not shown, in 736 particular since $\mathrm{K}$ is a good tracer for chemical alteration of the orthoclase structure. The omnipresence 737 of carbon, which makes up the resin, makes this technically very difficult because the $\mathrm{K} L_{2,3}$ and the $\mathrm{C} K$ 738 ionization edges are nearly at the same energy. Deconvoluting the $\mathrm{K}$ and $\mathrm{C}$ EEL spectral signatures is 739 technically very difficult, and thus was not attempted. The other major $\mathrm{K}$ absorption edges could 740 theoretically be used, but they occur at either too high ( $K$ edge at $3607 \mathrm{eV}$ ) or too low energy $\left(M_{2,3}\right.$ edges 741 at $18 \mathrm{eV}$ ), such that in practice it would be difficult to extract a quantitative signal to calculate an image.

\subsubsection{Advanced STEM-EDX: the effect of electron dose}

The K/Si values measured in areas 1-3 in Fig. 4a bring up an important point, as K/Si ratios were often anonymously low at orthoclase grain edges when compared to regions a few hundreds of nm towards the interior of the grain. These elemental concentrations were measured with the Tecnai TEM using a $1 \mathrm{nA}$ probe current $\left(24.9^{\circ}\right.$ sample tilt). We therefore proceeded to investigate this in more detail by measuring $\mathrm{K} / \mathrm{Si}$ values at another close by area on the same orthoclase grain edge with an advanced analytical TEM, the aberration corrected Titan Themis (Minatec). For these measurements we used a 
751 the interface confirmed that nominal, unaltered orthoclase K/Si values were obtained. Thus, the low K/Si 752 values described above (section 3.3.1, Fig. 4a) are clearly an analytical artifact. This example illustrates 753 the advantages of using a 4-detector EDXS system that allows for very fast X-ray acquisition times 754 using very low beam currents. These results also point out that orthoclase grain edges, perhaps due to a 755 thickness effect, are more prone to alkali diffusion than grain interiors, in particular when too high beam 756 currents are used, or if the acquisition time is too long (refer also to study by van der Pluijm et al., 1988).

757 Going further, to quantify the importance of the electron dose on $\mathrm{K}$ and Na measurements, we 758 measured the EDXS counts of $\mathrm{K}, \mathrm{Na}, \mathrm{Al}$, and $\mathrm{Si}$ on several consecutive, same-sized areas of orthoclase 759 sample CSY-1C as a function of the total electron dose. The measurements were made towards the 760 interior of the grain, and away from the edge. The dose is defined as the number of electrons that 761 impinge upon $1 \mathrm{~nm}^{2}$ of surface, and is expressed in units of $\mathrm{pA} \cdot \mathrm{s} \cdot \mathrm{nm}^{-2}$. Figure 7 schematically shows the 762 evolution of the stoichiometrically normalized elemental ratios, expressed in terms of $\mathrm{Si} / 3 \mathrm{Al}$, $763(\mathrm{~K}+\mathrm{Na}) / \mathrm{Al}, \mathrm{K} / \mathrm{Al}$, and $\mathrm{Na} / \mathrm{K}$. All of the ratios are fitted to discreet linear trends over the entire range of 764 electron doses probed. The linear and constant trend defining Si/3Al indicates that Si and Al are not 765 affected by electron doses inferior to $0.7 \mathrm{pA} \cdot \mathrm{s} \cdot \mathrm{nm}^{-2}$. The $\mathrm{Na} / \mathrm{Al}$ trend can be interpreted in terms of a 766 very slight loss of $\mathrm{Na}$ with increasing dose in the ' $\mathrm{K}, \mathrm{Na}$ loss region' of Fig. 7. On the other hand, the $767 \mathrm{~K} / \mathrm{Al}$ and $(\mathrm{K}+\mathrm{Na}) / \mathrm{Al}$ intensities appear to be roughly constant in the low dose region $\left(<0.15 \mathrm{pA} \cdot \mathrm{s} \cdot \mathrm{nm}^{-}\right.$ $762^{2}$ ), but then show a marked linear decrease at higher doses. These results, somewhat surprisingly, 769 indicate that $\mathrm{K}$ is much more susceptible to electron dose-induced thermal diffusion compared to Na. 770 Overall, the relations shown in Fig. 7 indicate that TEM-EDX measurements are best done in the "no 771 loss' region corresponding to a total dose $<0.15 \mathrm{pA} \cdot \mathrm{s} \cdot \mathrm{nm}^{-2}$, in particular for measurements at thinner 772 edge regions. Taken together, these results confirm that the anomalously low K/Si values often 773 measured in areas close to K-feldspar grain edges are most likely due to too high electron doses (e.g., 774 area 3, Fig. 4a).

\subsubsection{Advanced STEM-HAADF-EDXS measurements of an interfacial SAL}

Using the Themis TEM, we obtained a moderate-resolution STEM-HAADF image of an interfacial region on orthoclase grain CSY-1C (Fig. 8). The vertical dashed line delimits the interface between the orthoclase and a presumably amorphous surface layer (SAL). A relative thickness profile on the STEMHAADF image, generated by iterative calculations using elemental X-ray intensities (Robin, 2017), reveals that the orthoclase edge region is thinner than the bulk material further away. There are also slight inhomogeneities in the grey tone of the orthoclase: a. the bottom half of the unaltered orthoclase 
783 region appears slightly lighter in color, b. numerous small white flecks are present on the orthoclase 784 surface, particularly evident on the right side of Fig. 8a. These inhomogeneities are probably due to 785 minor redeposition (sputtering) of the adjacent amorphous material (SAL) that occurred either during 786 FIB milling, or EDXS analyses. The amorphous material is probably composed of a 'soft' gel-like 787 material that is easily prone to electron or ion beam sputtering.

788 Figure 8 also shows normalized chemical profiles that were determined along the same trace used 789 for the thickness profile. The K/Al profile is characterized by a nm-sharp, step function-like jump at the 790 interface between the orthoclase grain edge and the abutting amorphous phase. The behavior of the K/Al 791 ratio as it transitions from orthoclase to the amorphous phase (SAL) is due to the combined effects of a 792 sharp increase in $\mathrm{K}$ concentrations and a concomitant decrease in Al. In contrast, the $\mathrm{Na} / \mathrm{Al}$ ratio remains 793 roughly constant in both phases. The profile of $\mathrm{Si} / 3 \mathrm{Al}$ is relatively constant, with a value near 1.0 within 794 the orthoclase. As the profile passes into the SAL, the ratio exhibits more variability, but remains close 795 to an average of 1.0 over a distance of 0 to $-30 \mathrm{~nm}$. At distances $<-30 \mathrm{~nm}$ the ratio shows a monotonic 796 but fluctuating increase to a value of $\sim 1.7$. The fluctuations may be due to pores or other 797 inhomogeneities in the SAL. The O/8Al profile displays virtually identical behavior to the $\mathrm{Si} / 3 \mathrm{Al}$ profile 798 in the orthoclase and over 0-30 nm within the SAL. However, at distances $<-30 \mathrm{~nm}$ in the SAL, the $799 \mathrm{O} / 8 \mathrm{Al}$ profile surpasses the $\mathrm{Si} / 3 \mathrm{Al}$ profile. One interpretation for $\mathrm{O} / 8 \mathrm{Al}>1$ is the presence of $\mathrm{H}_{2} \mathrm{O}$, 800 indicating hydration of the SAL. The largest positive spikes in the O/8Al profile may in fact correspond 801 to water inclusions. Even without a statistical analysis, there is a surprising correlation between many of 802 the $\mathrm{Si} / 3 \mathrm{Al}$ and $\mathrm{O} / 8 \mathrm{Al}$ profile peaks in the SAL. One final note concerning the potential redeposition of amorphous material onto the orthoclase surface; there is no effect on the $\mathrm{Na} / \mathrm{Al}, \mathrm{Si} / 3 \mathrm{Al}$, and $\mathrm{O} / 8 \mathrm{Al}$ profiles, and only a very insignificant effect on the $\mathrm{K} / \mathrm{Al}$ profile within the orthoclase.

The STEM-HAADF image in Fig. 9a is derived from a cropping of Fig. 8a, thereby allowing 806 additional details of the interface to be more clearly shown. This image clearly shows a prominent and sharp vertical interface (white arrows) that marks a sudden transition in both structure and chemistry, which is manifested by a difference in mass-density between the orthoclase (right) and an amorphous SAL (left) with lower mass-density. The even less dense large pores appear black, in particular the bottom most one. The presence of such large pores can be construed as indirect evidence for the amorphous nature of the SAL- note also their morphological resemblance to those in Fig. 4a-c. The origin of the thin vertical band that appears at the external edge region of the orthoclase is not understood, but it may be an artifact.

Figure $9 \mathrm{~b}$ is a superposition of $\mathrm{K}, \mathrm{Ca}$, and Si EDXS maps onto the STEM-HAADF image, after a 815 'smooth' filter was applied. The corresponding individual elemental (Ca, K, Al, Si) EDXS maps, which 
have also been superposed on the same STEM-HAADF image, are shown in Fig. 9c. The individual 817 concentrations (i.e. colors) in the latter maps are based on non-background corrected raw counts 818 (background counts were negligible). The $\mathrm{Al}$ and $\mathrm{Si}$ maps reveal that the orthoclase-SAL chemical interface is extremely sharp at the nm-scale, due to step function-like drops in their respective concentrations in the SAL. The interface on the $\mathrm{K}$ map is less obvious, mainly because the concentration gradient across the boundary is much less important, in particular at the interface in the upper part of Fig. 9c. Calcium is distributed exclusively, but inhomogeneously, in the SAL. Calcium concentrations are highest further away from the orthoclase interface, with lower levels present in the 70-nm thick part of the SAL abutting the orthoclase. Note that the presence of tiny red-colored flecks on the orthoclase surface is an artifact due to redeposition, and is not representative of any penetration of $\mathrm{Ca}$ into the orthoclase structure (see previous discussion above).

The superposition of several elemental maps shown in Fig. $9 b$ affords a multi-element view of the sharp orthoclase-SAL interface, as well as how $\mathrm{Ca}, \mathrm{K}$, and $\mathrm{Si}$ are spatially co-distributed in the SAL. As was the case in Fig. 9c, the chemical interface is spatially coincident with the mass-density interface in Fig. 9a. The vertically oriented chemical interface between the unaltered orthoclase grain (blue, right side) and the secondary precipitate (green and red, left side) is indicated by the white arrows. The orthoclase does not have a homogeneous blue color, as indicated by the presence of green patches in the lower half of the image- the possible reasons for this are discussed directly above. The transition from orthoclase to SAL (i.e., blue to green) is in particular characterized by a sharp decrease in Si and concomitant moderate increase in $\mathrm{K}$. The SAL adjacent and to the left of the orthoclase interface is characterized in particular by high levels of $\mathrm{K}$ (vivid green color), while further away ( $>\sim 70 \mathrm{~nm}$ ) it is enriched in $\mathrm{Ca}$. Nonetheless, the distribution of red flecks within green, K-rich region indicates that $\mathrm{Ca}$ is distributed throughout the SAL, even where it abuts the orthoclase interface. The decrease in $\mathrm{K}$ concentrations roughly $70 \mathrm{~nm}$ distant from the interface corresponds to the predominance of the vivid red color at the far left of the image, indicating higher $\mathrm{Ca}$ concentrations. The limit between K-rich and Ca-rich regions in the SAL is irregular and not abrupt. Given the elevated Ca concentrations it is possible that amorphous or nanocrystalline calcium carbonate is a component of SAL. In general, the SAL also contains $\mathrm{Si}$ (and Al- see Fig. 9c), but at lower levels compared to the orthoclase (Si appears as dark blue-purple within the SAL). We also remark that it is likely that the SAL is water-enriched, but that quantification of $\mathrm{H}$ is not possible by EDXS.

The most significant finding here is the presence of this $\sim 70-\mathrm{nm}$ wide K-enriched SAL that directly contacts the orthoclase interface (note that the full thickness of the SAL is $>70 \mathrm{~nm}$ ). To better compare 
concentrations (X-ray absorption-corrected) were first made within the orthoclase (i.e. in the bluecolored area to the right of the interface, Fig. 9b)- these yielded the nominal composition of unaltered orthoclase, thereby indicating that the orthoclase retained its composition during alteration. Calcium levels were below the analytical limit, evidence that $\mathrm{Ca}$ substitution or replacement of the orthoclase structure did not occur. The same type of quantitative, X-ray absorption-corrected EDXS measurement of the chemical composition of the SAL was effected in the rectangular area in Fig. 8b. The results are given below and in Table 3 in atom \% (atom \% is preferred over weight \% since atomic ratios can be immediately compared to values derived from Table 1):

$$
\begin{aligned}
& \mathrm{C}=6.5 \\
& \mathrm{Na}=0.74 \\
& \mathrm{Ca}=5.13 \\
& \mathrm{~K}=11.41 \\
& \mathrm{Si}=15.94 \\
& \mathrm{Al}=4.81 \\
& \mathrm{O}=55.45
\end{aligned}
$$

863

864

865

The chemical composition of the analyzed area confirms that the amorphous phase is very rich in K, 866 with a concentration significantly greater than that in the proximal unaltered orthoclase (i.e. XRF867 derived [ $\mathrm{K}_{\text {orthoclase CSY-1] }}$ is 5.2 atom \% - see Table 1). We note that the concentrations of $\mathrm{Al}$ and Si in the 868 SAL are 3 and 7 atom \% less, respectively, than their XRF-measured concentrations in orthoclase 869

870

871 sample CSY-1 (Table 1). The average spectrum (not shown) corresponding to the rectangular area reveals that the $\mathrm{C} K$ peak is convoluted with the $\mathrm{K}$ and $\mathrm{Ca} L$ peak; thus, the error in the quantitative estimate for $\mathrm{C}(\sim 10 \%)$ is higher than for the other elements: $\mathrm{Si}, \mathrm{Al}, \mathrm{K}, \mathrm{Na}, \mathrm{Ca}$, and $\mathrm{O}(\sim 6 \%)$.

872

873

\subsubsection{Atomic resolution imaging of orthoclase-SAL interface}

874

875

876

Numerous high-resolution TEM (HRTEM) images of the interfacial region (CSY-1C and CSY-3C) always show a near-atomically sharp and relatively linear structural interface. Figure 10 is a typical example of such an interface (white arrows)- the high-resolution image stems from an interface close to that in Fig. 9. In this particular area, the amorphous layer is many tens of nm thick. Here one can see lattice fringes terminating abruptly at the amorphous secondary precipitate. However, in some regions of 879 the interface, the fringes are blurry and appear to extend beyond the interface into the amorphous phase. There are two possible reasons for this: a delocalization effect, or more probably, a highly inclined (oblique) and/or non-planar, irregular interface. It should be remembered that the interface has a considerable thickness, at least on the order of $\sim 150 \mathrm{~nm}$, which is the approximate thickness of the FIB 
883

884

885

886

887

888

889

890

891

892

893

894

895

896

897

898

899

900

901

902

903

904

905

906

907

908

909

910

911

912

913

914

lamella. It is to be expected that over such a distance the interface will not be perfectly planar and vertical. The non-crystallinity of the amorphous layer was verified by fast Fourier transform (FFT).

\section{Discussion of dissolution mechanism}

Our results show the ubiquitous presence of a continuous layer of amorphous material abutting primary orthoclase grains. This SAL is variable in thickness, ranging from under ten $\mathrm{nm}$ to approximately $200 \mathrm{~nm}$. When imaged at moderate to high resolution, the structural interface between the orthoclase and the SAL is sharp at the 1-2 nm scale, and is spatially coincident with a very abrupt chemical boundary characterized by distinct decreases in $\mathrm{Al}$ and $\mathrm{Si}$. The interface is also characterized by important concentrations of $\mathrm{Ca}$ on the SAL side, and its virtual absence on the orthoclase side. Very importantly, the SAL also contains variable and elevated concentrations of $\mathrm{K}$. Our nm-scale measurements point to a first-time observed K-rich authigenic phase that forms directly and in situ at the receding interface of orthoclase during dissolution at alkaline conditions. This amorphous SAL is by far a more significant reservoir of $\mathrm{K}$ than hitherto measured in previous studies.

In section 3.1 we report that one sample has a moderate amorphous content of $\sim 16$ mass \% (sample CSY-1C-a). Based on this measurement, we speculate that discreet amorphous phases also formed elsewhere in the hydrothermal product, in particular within the amalgam of secondary authigenic phases.

We did not characterize these potential occurrences of amorphous material, as our investigation was restricted to the interfacial region of orthoclase grains. As far as we know, the only comparable analysis of an amorphous phase produced during alkaline alteration of a K-feldspar can be found in Ciceri et al. (2017a). Their study revealed the presence of amorphous grains that contain on average $3.6 \mathrm{wt} \% \mathrm{~K}$.

During chemical alteration the original orthoclase grains dissolve and decrease in volume and mass, but at the nanometer to micron scale, the remaining orthoclase grain cores do not show evidence for chemical alteration, as they retain their nominal, bulk chemical composition (section 3.3.5), even at grain edges (Figs. 8, 9). In addition, all grain edges are characterized by sharp structural reaction interfaces, as evidenced by orthoclase lattice fringes terminating abruptly at the boundary with the SAL (Fig. 10). These two observations are evidence that dissolution is congruent (i.e. stoichiometric) and proceeds via a sharp reaction front that consumes the parent orthoclase structure.

One immediate question that comes to mind is why $\mathrm{K}^{+}$, a labile cation, was not preferentially leached from the orthoclase structure during alteration, thereby leading to the formation of K-deficient leached layers? This traditional idea of leached layer formation during dissolution can be dismissed for many reasons. First, the replacement of $\mathrm{K}^{+}$by $\mathrm{H}^{+}\left(\right.$or $\left.\mathrm{H}_{3} \mathrm{O}^{+}\right)$from the solution can be discounted because 
915 the concentration of $\mathrm{H}^{+}$in the solvent is vanishingly small in a strong alkaline solution with very high $916 \mathrm{pH}$. This would render such an exchange process improbable. Moreover, leached layer formation is 917 controlled by interdiffusion (e.g., Hellmann et al., 2012; and references therein), and such a solid-state 918 process is orders of magnitude too slow at the $190{ }^{\circ} \mathrm{C}$ temperature of the experiments. And finally, 919 replacement of $\mathrm{K}^{+}$by $\mathrm{H}^{+}$would be incompatible with the orthoclase structure. Note that there is no 920 evidence of a change in lattice fringe spacing at the orthoclase edge in Fig., 10.

921 A second question we can ask is why K-Ca exchange did not occur, such as postulated by Ciceri et 922 al. (2017a). This would entail the preferential loss of $\mathrm{K}^{+}$from the orthoclase structure, coupled to an 923 interdiffusion-controlled substitution by $\mathrm{Ca}^{2+}$ ions from the solvent, leading to the in situ formation of a 924 Ca-rich plagioclase phase. A diffusion-controlled mineral replacement process would require evidence 925 for anti-correlated and sigmoidal interdiffusion-coupled Ca-K profiles (see, e.g. Hellmann et al., 2012). 926 Chemical analyses and nm-scale chemical mapping of the orthoclase interfacial region (Figs. 6, 9), 927 however, show no evidence for the penetration of $\mathrm{Ca}$ into the orthoclase structure. In addition to this, an 928 exchange process is theoretically difficult to envision due to the substantial size difference between 929 univalent $\mathrm{K}^{+}$and divalent $\mathrm{Ca}^{2+}$. Moreover, the formation of Ca-plagioclase reaction rind $\left(\mathrm{KAlSi}_{3} \mathrm{O}_{8} \rightarrow\right.$ $930 \mathrm{CaAl}_{2} \mathrm{Si}_{2} \mathrm{O}_{8}$ ) would also require a net addition of $\mathrm{Al}$ and a loss of $\mathrm{Si}$ to the original orthoclase structure. 931 Again, we see no evidence for a gain of Al and loss of Si in the orthoclase structure, in particular at grain 932 edges (Figs. 8, 9). As briefly mentioned above, a solid-state diffusive process at $190^{\circ} \mathrm{C}$ is simply too 933 slow to render such a change in chemistry over the $24 \mathrm{~h}$ time span of these experiments. It should be 934 remembered that solid-state diffusional processes are exceedingly slow compared to chemical reactions 935 such as dissolution and/or precipitation below $\sim 500{ }^{\circ} \mathrm{C}$ (see, e.g., Villa, 2016). In fact, in nature the 936 solubility of $\mathrm{Ca}$ in $\mathrm{K}$-feldspar at low temperatures is insignificant- only at higher temperatures can minor 937 amounts of $\mathrm{Ca}$ be incorporated into K-feldspar structures. This explains why, in fact, the unaltered K938 feldspars used in this study contain only trace amounts of Ca (Table 1).

939 The results we present strongly support a different mechanism that controls the hydrothermal 940 alkaline alteration of K-feldspar, and stands in opposition to nearly all previous studies in this field. As 941 elucidated in the Introduction (section 1.3), the prevailing opinion is that alteration of alkali feldspars 942 occurs either by congruent dissolution, or by preferential leaching of $\mathrm{K}$ and replacement by another 943 charge-compensating cation from solution. Our experimental results concur with the process of 944 congruent dissolution, which in turn is accompanied by precipitation of predominantly crystalline 945 secondary phases (calcite, hydrogrossular, tobermorite) from an oversaturated bulk solution. Where our 946 interpretation differs from nearly all other studies (at alkaline $\mathrm{pH}$ conditions) is that we have measured 
947 the in situ formation of a significant amorphous phase that forms directly at the interface and at the 948 expense of the dissolving orthoclase structure. We postulate that this amorphous SAL starts to form right 949 at the onset of contact with the solvent fluid, and continues to form as the feldspar interface continuously 950 recedes during dissolution. The interfacial process we are proposing represents a physically plausible 951 process that concurs with our nm-scale observations and measurements. We refer to this process as 952 coupled interfacial dissolution-reprecipitation, or CIDR (Hellmann et al., 2003, 2012, 2015). As 953 discussed further on, this is a relatively new theory, and has been the subject of other chemical alteration 954 studies concerning both silicate minerals and glasses. This same mechanism has also been applied to 955 pseudomorphic mineral-mineral replacement reactions, where it has been referred to as interfacial956 coupled dissolution-(re)precipitation, or ICDP (Putnis, 2002; Putnis et al., 2005; Geisler et al., 2005; and 957 references therein).

958 Based on our finding of an abrupt and spatially coincident chemical and structural discontinuity 959 at the interface between the edge of the orthoclase structure and the amorphous SAL, we advocate the 960 CIDR mechanism (O'Neil and Taylor, 1967; Buck et al., 2000; Hellmann et al., 2003, 2012, 2015; 961 Putnis, 2002, 2009). This mechanism is based on the advance of a sharp chemical reaction front into the 962 unaltered parent phase, with stoichiometric dissolution occurring within a thin fluid film (O'Neil and 963 Taylor, 1967) of ordered solvent molecules (Thomä et al., 2019; Parker et al., 2001; Khatib et al., 2016) 964 at the reactive interface (Hellmann et al., 2015). Released elements that are insoluble synchronously 965 reprecipitate at the interface, without first passing into the bulk solution, whereas soluble elements 966 migrate to the bulk solution. The thin fluid film possesses physico-chemical and rheological properties 967 that differ from the bulk fluid (Fenter and Sturchio, 2004; Marry et al., 2008; Knight et al., 2019), and 968 thus reprecipitation of a secondary phase is possible even when the bulk solution is chemically under969 saturated with respect to secondary phases (Hellmann et al., 2003, 2012, 2015; Ruiz-Agudo et al., 2012). 970 The tight spatial and temporal coupling of dissolution and reprecipitation within an interfacial fluid film 971 is one of the main characteristics that differentiates CIDR from a classical precipitation process 972 associated with a chemically oversaturated bulk solution.

973 How and when the amorphous phase formed is a key to understanding the overall dissolution 974 process in our study, and in particular, the mechanism of dissolution. The spatial ordering of the 975 secondary phases shows that the amorphous phase was initially the first phase to form. With increasing 976 reaction progress, secondary crystalline phases started to massively precipitate on top of the amorphous 977 SAL as the bulk fluid became increasingly saturated with solute. The reasons for chemical 978 oversaturation are multiple: dissolution of the orthoclase grains, a steadily decreasing fluid-solid ratio, 979 cooling at the end of the experiment, and finally, evaporation of any remaining fluid during the final heat 
treatment step. All of these contributed to chemical supersaturation of the bulk solution and the classical

981 precipitation of the secondary crystalline phases. It is interesting to note that the overall morphology of 982 our reacted orthoclase grains, characterized by a relatively thin amorphous SAL overlain by a 1-2 $\mu \mathrm{m}$ 983 thick rind of secondary crystalline phases, has a counterpart in a study of a naturally altered K-feldspar 984 that has a $10 \mathrm{~nm}$-thick amorphous SAL covered by a thick 3-5 $\mu$ m layer of authigenic smectite (Zhu et 985 al., 2006).

The experimental protocol did not permit us to periodically sample the solution phase, nor 987 retrieve orthoclase grains before the end of each experiment. Nonetheless, we argue that the amorphous phase is not a classical precipitate, but rather formed in situ by CIDR, and its growth was initiated upon contact of the fluid with the orthoclase grains. Based on solubility arguments, if the amorphous phase had been a classical precipitate, it would have formed on top of the less soluble secondary crystalline phases, but the FESEM and TEM images clearly show that this was not the case. In addition, we use experimental data from a previous study (Hellmann, 1995) to further this argument. In that particular study, the release of $\mathrm{Na}, \mathrm{Al}$ and $\mathrm{Si}$ was continuously measured during hydrothermal alteration of albite feldspar in a flow reactor at $200{ }^{\circ} \mathrm{C}$ and $\mathrm{pH} 12 \mathrm{KOH}$ solution- we note that albite and orthoclase have similar structures; in addition, the alteration conditions were very close to those in the present study. While a mechanism describing how the parent solid reacts cannot be deduced solely from aqueous cation release curves, the release curves do show that right from the beginning of the experiment, the aqueous solutions show non-stoichiometry (Hellmann, 1999b), even though the solution was very undersaturated with respect to secondary crystalline phases. This data by itself can be interpreted to mean that a surface interfacial process was continuously operative in the experiment by Hellmann (1995). Going further, the Hellmann data supports our argument that an interfacial process starting right at the onset, and continuing throughout the experiment, resulted in interfacial precipitation of an amorphous SAL. Other studies in the literature concur with this idea, namely those that have measured dissolution in situ. These published experiments, at ambient and hydrothermal conditions, have measured in real time and in situ the initial reaction between silicate minerals and aqueous fluids (Hellmann, 1999a; Hellmann et al., 1992; Putnis et al., 2005; Ruiz-Agudo et al., 2012; Jordan et al., 1999; Fenter et al., 2000; Teng et al., 2001; Leonard and Hellmann, 2017). These studies all show the rapid in situ formation of a surficial gel-like phase that is an amorphous interfacial reprecipitate.

It is interesting to speculate why we did not document a pseudomorphic replacement reaction involving a Ca-rich plagioclase. Feldspar-feldspar replacement reactions in nature and experiment are widely cited (O'Neil and Taylor, 1967; Parsons and Lee, 2009; Parsons et al., 2009; Lee and Parsons, 1997; Labotka et al., 2004; Cole et al., 2004; Engvik et al., 2008; Hövelmann et al., 2010; Norberg et al., 
1013 2011; Ruiz-Agudo et al., 2014). Because CIDR is a fluid-assisted alteration process that is thought to 1014 occur in a thin interfacial fluid film, it is theoretically possible that a Ca-rich crystalline phase, such as 1015 Ca-rich plagioclase (labradorite, anorthite), could have formed at the reactive interface- as the argument 1016 of $\mathrm{Ca}^{+2}$ and $\mathrm{K}^{+}$incompatibility due to ionic radius and charge, as well as too slow solid-state 1017 interdiffusion, would not be relevant. However, in our study, the SAL that formed was amorphous. 1018 Given that CIDR is a fluid-mediated chemical alteration mechanism, and not a solid-state process, it 1019 should be possible from a strictly theoretical point of view to form a Ca-rich plagioclase phase within 1020 the interfacial fluid, provided that the chemical components are present in the correct stoichiometric 1021 proportions and concentrations. However, there was no evidence for this having occurred. At this point 1022 we can only surmise a few reasons that possibly favored reprecipitation of an amorphous phase: $i$. a too

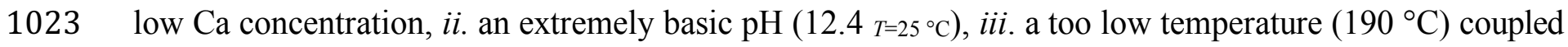
1024 to a very short time period $(24 \mathrm{~h})$. Perhaps over geological periods of time and at much higher 1025 temperatures, it may be possible to precipitate a Ca-rich plagioclase phase in the context of a mineral1026 mineral replacement reaction. Future experiments at higher $T, P$ conditions, or over longer time periods, 1027 could perhaps answer this question. It is interesting to note that the reverse process, the albitization of 1028 plagioclase, has been experimentally documented at $600{ }^{\circ} \mathrm{C}, 2 \mathrm{kbars}$ in an aqueous Na-silicate solution 1029 (Hövelmann et al., 2010).

1030 Many frontier questions on the CIDR mechanism still remain. Since the reprecipitated layer 1031 initially forms at the interface, presumably within the extremely thin interfacial fluid film in contact with 1032 the parent mineral structure, it remains to be determined whether this fluid film of ordered solvent 1033 molecules is continuous, or not. During chemical alteration, the dissolution of the primary phase 1034 (orthoclase) is a continuous process, and it is at the 'inner edge' of the SAL where new material is 1035 precipitated. The chemical stability of the reprecipitated material within the thin fluid film will in large 1036 part determine its chemical composition. Although we don't know what the $\mathrm{pH}$ was in the fluid film, it 1037 was undoubtedly very basic (close to the value in the bulk fluid), and at such conditions, Si and Al 1038 oxides or oxyhydroxides are very soluble. This may explain the lower levels of Al and Si that were 1039 measured in the SAL, as compared to their nominal concentrations in orthoclase. Nonetheless, the Si and 1040 Al that did precipitate in the layer (i.e., Fig. 9) would likely be in the form of $\mathrm{Si}^{-} \mathrm{O}^{-}$and Al-O- groups, as 1041 these groups predominate at very basic $\mathrm{pH}$ conditions. Released $\mathrm{K}^{+}$ions may preferentially adsorb to 1042 these negatively charged sites. It nonetheless remains an open question as to why the K concentration in 1043 the SAL is so conspicuously elevated. As the amorphous layer grows in thickness over time, the first1044 formed and older 'outer edge' will be in contact with the free bulk fluid, or fluid within pores and 1045 channels of any overlying secondary crystalline precipitates that formed. Therefore, the chemical 
1046

1047

1048

1049

1050

1051

1052

1053

1054

1055

1056

1057

1058

1059

1060

1061

1062

1063

1064

1065

1066

1067

1068

1069

1070

1071

1072

1073

1074

1075

1076

1077

stability of the outer interface of the SAL, which controls its dissolution behavior, will be dictated by the chemical properties of the bulk fluid, and not the thin interfacial fluid film. A more detailed understanding of the composition and exact nature of the amorphous interfacial layer calls for additional research, in particular using other complementary techniques, such as X-ray adsorption or nanoRaman/FTIR. One last question that perhaps deserves further study is whether the amorphous SAL, as well as the enveloping rind of secondary authigenic minerals, eventually hinder, or at least slow down, the kinetics of the orthoclase dissolution reaction. A similar question was also posed by Zhu et al. (2006) concerning their estimation that a naturally weathering Jurassic-aged K-feldspar was dissolving 5 orders of magnitude slower than K-feldspar in far-from-equilibrium laboratory experiments at comparable $\mathrm{pH}$ and $T$ conditions. They attributed this significant difference to the presence of a $10 \mathrm{~nm}$ thick amorphous SAL, surface-adhering kaolin platelets, and a thick outer rind of authigenic smectite.

\section{Conclusions}

To extend our thoughts concerning the present study, an interfacial amorphous phase has been documented to form in situ at the expense of orthoclase at strong alkaline conditions. Amorphous SALs have been previously documented to form on feldspars at acid, near-neutral and weak alkaline $\mathrm{pH}$ conditions, with $\mathrm{pH}$ controlling their thickness. They are significantly thicker at acid $\mathrm{pH}$ than those that form at near-neutral and moderate basic pH (Hellmann et al., 2003, 2012; Lee et al., 2007). As discussed in detail in section 1.3, the majority of studies on feldspars from the 1990s and early 2000s postulated that SALs (even when very thin) form by an interdiffusion process, leading to leached layers. Despite the pioneering study of O'Neil and Taylor in 1967, it has only been over the past 20 years that natural and experimental feldspar dissolution studies at acid and near-neutral $\mathrm{pH}$ conditions, and in particular amorphous SAL and mineral-mineral replacement reactions, have been conceptually framed within the context of CIDR and CIDR-like mechanisms (e.g., Hellmann et al., 2003, 2012; Lee et al., 2007; Parsons and Lee, 2009; Labotka et al., 2004; Hövelmann et al., 2010; Ruiz-Agudo et al., 2014). A theoretical Monte Carlo approach also supports the CIDR mechanism for plagioclase dissolution mechanisms (Zhang and Lüttge, 2009). Perhaps the most significant contribution our new data make is filling an important knowledge gap on the mechanism of K-feldspar dissolution in strong alkaline solutions. Thus, this study can be considered to be a unifying element in terms of the dissolution process of alkali feldspars over the full range of $\mathrm{pH}$ conditions, and at temperatures up to an including hydrothermal conditions. Only further research will contribute to answering the question as to whether CIDR is a generic and universal mechanism of chemical alteration for all feldspars and other silicate 
minerals in aqueous solutions over a broad range of $\mathrm{pH}$ and temperature conditions.

\section{Acknowledgements}

1085

1086

1087

1088

1089

1090

1091

1092

1093

1094

1095

1096

1097

1098

1099

1100

1101

1102

\section{3}

1104

1105

1106

1107

1108

1109

1110

1111

1112

1113

1114

1115

1116

1117

1118

1119

1120

1121

1122

1123

1124

The initial phase of this study was supported by Projects in the National Science \& Technology Pillar Program during the Eleventh Five-Year Plan Period (China, No. 2006BAD10B04) and the Knowledge Innovation Project of the Chinese Academy of Sciences and the Spark Program of China (No. 2007EA173003). The aforementioned funding covered the procurement of the orthoclase samples in the field, chemical characterization by X-ray fluorescence, hydrothermal alteration in the laboratory, and leaching experiments followed by aqueous ICP analyses. The one-year stay of YZ (Nov. 2017-Nov. 2018) with the RH research group at ISTerre, Grenoble, France was financed by a State Scholarship Fund organized by the China Scholarship Council. The analytical, instrumental, and travel costs in France were supported by two ISTerre-BQR grants. B. Lanson's (ISTerre) expertise with XRD and Rietveld refinement is gratefully acknowledged, as is the valuable assistance for the BET analyses by V. Magnin (ISTerre). The geochemistry-mineralogy platform of ISTerre is partially funded by a grant from Labex OSUG@2020 (investissements d'avenir, ANR10-LABX56). We are particularly thankful for the FIB, FESEM and TEM beam time provided by Section 3.5, Interface Geochemistry (head: L. Benning), GFZ Potsdam, Germany. The financial support of the Helmholtz Recruiting Initiative (grant No. I-04416-01) is acknowledged. We also thank J. Hughes (Univ. Vermont) for useful discussions. We thank an anonymous reviewer and the chief editor, M. Böttcher, for helpful comments that improved the manuscript.

\section{References}

Arnold, G.W., Westrich, H.R., Casey, W.H., 1992. Application of ion beam analysis (RBS and ERD) to the surface chemistry study of leached minerals. Nuclear Instruments Methods Phys. Res., B 64, 542-546.

Bandstra, J.Z., Buss, H.L., Campen, R.K., Liermann, L.J., Moore, J., Hausrath, E.M., Navarre-Sitchler, A.K., Jang, J. H., Brantley, S.L., 2008. Appendix: Compilation of mineral dissolution rates. In: Brantley, S.L., Kubicki, J.D., White, A.F. (Eds.), Kinetics of Water-Rock Interaction, Springer, New York, pp. 737-823.

Bergmann, J. (2005) Rietveld Analysis Program BGMN (http://www.bgmn.de/BGMN manual 2005.pdf).

Blum, A.E., Stillings, L.L., 1995. Feldspar dissolution kinetics. In: White, A.F., Brantley, S.L. (Eds.), Chemical Weathering Rates of Silicate Minerals. Mineralogical Society of America, Washington, D.C., pp. 291-351.

Brown, W.L., Parsons, I., 1989, Alkali feldspars: ordering rates, phase transformations and behavior diagrams for igneous rocks. Mineral. Mag. 53, 25-42.

Buck, E.C., Smith, K.L., Blackford, M.G., 2000. The behavior of silicon and boron in the surface of corroded nuclear waste glasses: An Eftem Study. Mat. Res. Soc. Symp. Proc. 608, 727-732.

Casey, W.H., Westrich, H.R., Arnold, G.W., 1988. Surface chemistry of labradorite feldspar reacted with aqueous solutions at $\mathrm{pH}=2$, 3, and 12. Geochim. Cosmochim. Acta 52, 2795-2807. 
Casey, W.H., Westrich, H.R., Arnold, G.W., Banfield, J.F., 1989a. The surface chemistry of dissolving labradorite feldspar.

Casey, W.H., Westrich, H.R., Massis, T., Banfield, J.F., Arnold, G.W., 1989b. The surface of labradorite feldspar after acid hydrolysis. Chem. Geol. 78, 205-218.

Chen, Y., Brantley, S.L., Ilton, E.S., 2000. X-ray photoelectron spectroscopic measurement of the temperature dependence of leaching of cations from the albite surface. Chem. Geol. 163, 115-128.

Ciceri, D., de Oliveira, M., Allanore, A., 2017a. Potassium fertilizer via hydrothermal alteration of K-feldspar ore. Green Chem. 19, 5187-5202.

Ciceri, D., Manning, D.A.C., Allanore, A., 2015. Historical and technical developments of potassium resources. Sci. Total Environm. 502, 590-601.

Ciceri, D., Oliveira, M.d., Stokes, R.M., Skorina, T., Allanore, A., 2017b. Characterization of potassium agrominerals: Correlations between petrographic features, comminution and leaching of ultrapotassic syenites. Mins. Eng. 102, 42-57.

Cliff, G., Lorimer, G.W., 1975. The quantitative analysis of thin specimens. J. Micros. 103, 203-207.

Chou, L., Wollast, R., 1985. Steady-state kinetics and dissolution mechanisms of albite. Am. J. Sci. 285, 963-993.

Cole, D.R., Larson, P.B., Riciputi, L.R., Mora, C.I., 2004. Oxygen isotopes zoning profiles in hydrothermally altered feldspars: estimating the duration of water-rock interaction. Geology 32, 29-32.

de la Torre, A.G., Bruque, S., Aranda, M.A.G., 2001. Rietveld quantitative amorphous content analysis. J. Appl. Cryst. 34, 196-202.

Döbelin, N., Kleeberg, R., 2015. Profex: a graphical user interface for the Rietveld refinement program BGMN. J. Appl. Cryst. 48, 1573-1580.

Dran, J.-C., Della Mea, G., Paccagnella, A., Petit, J.-C., Trotignon, L., 1988. The aqueous dissolution of alkali silicate glasses: reappraisal of mechanisms by $\mathrm{H}$ and Na depth profiling with high energy ion beams. Phys. Chem. Glasses 29, 249-255.

Engvik, A.K., Putnis, A., Gerald, J.D.F., Austrheim, H., 2008. Albitization of granitic rocks: the mechanism of replacement of oligoclase by albite. Can. Miner. 46, 1401-1415.

Fenter, P., Sturchio, N.C., 2004. Mineral-water interfacial structures revealed by synchrotron X-ray scattering. Progress Surf. Sci. 77, 171-258.

Fenter, P., Lee, S.S., Park, C., Catalano, J.G., Zhang, Z., Sturchio, N.C., 2010. Probing interfacial reactions with X-ray reflectivity and X-ray reflection interface microscopy: Influence of $\mathrm{NaCl}$ on the dissolution of orthoclase at pOH 2 and $85{ }^{\circ} \mathrm{C}$. Geochim. Cosmochim. Acta 74, 3396-3411.

Fenter, P., Teng, H., Geissbühler, P., Hanchar, J.M., Sturchio, N.C., 2000. Atomic-scale structure of the orthoclase (001)water interface measured with high-resolution X-ray reflectivity. Geochim. Cosmochim. Acta 64, 3663-3673.

Gautier, J.-M., Oelkers, E.H., Schott, J., 1994. Experimental study of K-feldspar dissolution rates as a function of chemical affinity at $150^{\circ} \mathrm{C}$ and $\mathrm{pH}$ 9. Geochim. Cosmochim. Acta 58, 4549-4560.

Geisler, T., Pöml, P., Stephan, T., Janssen, A., Putnis, A., 2005. Experimental observation of an interface-controlled pseudomorphic replacement reaction in a natural crystalline pyrochlore. Amer. Mineral. 90, 1683-1687.

Grogger, W., Schaffer, B., Krishnan, K.M., Hofer, F., 2003. Energy-filtering TEM at high magnification: spatial resolution and detection limits. Ultramicroscopy, 96, 481-489.

Harlov, D.E., Förster, H.-J., Nijland, T.G., 2002. Fluid-induced nucleation of (Y + REE)-phosphate minerals within apatite: Nature and experiment. Part I. Chlorapatite. Amer. Miner. 87, 245-261. 
1184

1185

1186

1187

1188

1189

1190

1191

1192

1193

1194

1195

1196

1197

1198

1199

1200

1201

1202

1203

1204

1205

1206

1207

1208

1209

1210

1211

1212

1213

1214

1215

1216

1217

1218

1219

1220

1221

1222

1223

1224

1225

1226

1227

1228

1229

1230

1231

1232

1233

1234

1235

1236

1237

1238

1239

1240

1241

1242

Hellmann, R., 1994. The albite-water system: Part I. The kinetics of dissolution as a function of $\mathrm{pH}$ at 100,200 , and $300^{\circ} \mathrm{C}$. Geochim. Cosmochim. Acta 58, 595-611.

Hellmann, R., 1995. The albite-water system: Part II. The time-evolution of the stoichiometry of dissolution as a function of $\mathrm{pH}$ at 100,200 and $300^{\circ} \mathrm{C}$. Geochim. Cosmochim. Acta 59, 1669-1697.

Hellmann, R., 1999a. The dissolution behavior of albite feldspar at elevated temperatures and pressures: the role of surface charge and speciation. Mitt. Österr. Mineral. Ges. 144, 13-44.

Hellmann, R., 1999b. Stoichiometry. In: Marshall, C.P. , Fairbridge, R.W. (Eds.), Encyclopedia of Geochemistry, Kluwer Academic Publishers, pp. 595-598.

Hellmann, R., Crerar, D.A., Zhang, R.H., 1989. Albite feldspar hydrolysis to $300{ }^{\circ}$ C. Solid State Ionics 32/33, $314-329$.

Hellmann, R., Drake, B., Kjoller, K., 1992. Using atomic force microscopy to study the structure, topography and dissolution of albite surfaces. In: Kharaka, Y.K., Maest, A.S. (Eds.), Water-Rock Interaction 7 Vol. I., Balkema, Rotterdam, pp. 149152.

Hellmann, R., Dran, J.-C., Della Mea, G., 1997. The albite-water system Part III. Characterization of leached and hydrogen-enriched layers formed at $300^{\circ} \mathrm{C}$ using $\mathrm{MeV}$ ion beam techniques. Geochim. Cosmochim. Acta 61, $1575-1594$.

Hellmann, R., Eggleston, C.M., Hochella, M. F., Jr., Crerar, D. A., 1990. The formation of leached layers on albite surfaces during dissolution under hydrothermal conditions. Geochim. Cosmochim. Acta 54, 1267-1281.

Hellmann, R., Penisson, J.-M., Hervig, R.L., Thomassin, J.-H., Abrioux, M.-F., 2003. An EFTEM/HRTEM high-resolution study of the near surface of labradorite feldspar altered at acid $\mathrm{pH}$ : evidence for interfacial dissolution-reprecipitation. Phys. Chem. Mins. 30, 192-197.

Hellmann, R., Wirth, R., Daval, D., Barnes, J.-P., Penisson, J.-M., Tisserand, D., Epicier, T., Florin, B., Hervig, R.L., 2012. Unifying natural and laboratory chemical weathering with interfacial dissolution-reprecipitation: A study based on the nanometer-scale chemistry of fluid-silicate interfaces. Chem. Geol. 294-295, 203-216.

Hellmann, R., Cotte, S., Cadel, E., Malladi, S., Karlsson, L.S., Lozano-Perez, S., Cabié, M., Seyeux, A., 2015. Nanometrescale evidence for interfacial dissolution-reprecipitation control of silicate glass corrosion. Nature Materials 14, 307-311.

Holdren, G.R., Jr., Speyer, P.M., 1985. pH dependent changes in the rates and stoichiometry of dissolution of an alkali feldspar at room temperature. Am. J. Sci. 285, 994-1026.

Hövelmann, J., Putnis, A., Geisler, T., Schmidt, B.C., Golla-Schinder, U., 2010. The replacement of plagioclase feldspars by albite: observations from hydrothermal experiments. Contrib. Miner. Petrol. 159, 43-59.

Jordan, G., Higgins, S.R., Eggleston C.M., Swapp, S.M., Janney, D.E., Knauss, K.G., 1999. Acidic dissolution of plagioclase: In-situ observations by hydrothermal atomic force microscopy. Geochim. Cosmochim. Acta 63, 3183-3191.

Kasioptas, A., Perdikouri, C., Putnis, C.V., Putnis, A., 2008. Pseudomorphic replacement of single calcium carbonate crystals by polycrystalline apatite. Mineral. Mag. 72, 77-80.

Khatib, R., Backus, E.H., Bonn, M., Perez-Haro, M.J., Gaigeot, M.P., Sulpizi, M., 2016. Water orientation and hydrogenbond structure at the fluorite/water interface. Sci. Reports 6, 24287.

King, H.E., Plümper, O., Geisler, T., Putnis, A., 2011. Experimental investigations into the silicification of olivine: Implications for the reaction mechanism and acid neutralization. Amer. Mineral. 96, 1503-1511.

Klein, C., Philpotts, A.R., 2017. Earth Materials: Introduction to Mineralogy and Petrology. In: Klein, C., Philpotts, A.R. (Eds.), Cambridge University Press, New York.

Knight, A.W., Kalugin, N.G., Coker, E., Ilgen, A.G., 2019. Water properties under nano-scale confinement. Sci. Reports 9, 8246. 
Labotka, T.C., Cole, D.R., Fayek, M., Riciputi, L.R., Stadermann, F.J., 2004. Coupled cation and oxygen-isotope exchange

Lee, M.R., Parsons, I., 1997. Dislocation formation and albitization in alkali feldspars from the Shap granite. Amer. Mineral. $82,557-570$.

Lee, M.R., Hodson, M.E., Parsons, I., 1998. The role of intragranular microtextures and microstructures in chemical and mechanical weathering: direct comparisons of experimentally and naturally weathered alkali feldspars. Geochim. Cosmochim. Acta $62,2771-2788$.

Lee, M.R., Brown, D.J., Smith, C.L., Hodson, M.E., Mackenzie, M., Hellmann, R., 2007. Characterization of mineral surfaces using FIB and TEM: A case study of naturally weathered alkali feldspars. Amer. Mineral. 92, 1383-1394.

Lee, M.R., Hodson, M.E., Brown, D.J., MacKenzie, M., Smith, C.L., 2008. The composition and crystallinity of the near-surface regions of weathered alkali feldspars. Geochim. Cosmochim. Acta 72, 4962-4975.

Leonard, D.N., Hellmann, R., 2017. Exploring dynamic surface processes during silicate mineral (wollastonite) dissolution with liquid cell TEM. J. Micros. 265, 358-371.

Liu, S. K., Han, C., Liu, J. M., Li, H. (2015) Hydrothermal decomposition of potassium feldspar under alkaline conditions. RSC Advances 5, 93301-93309.

Liu, S.K., Han, C., Liu, J.M., 2018. Study of K-feldspar and lime hydrothermal reaction at $190{ }^{\circ} \mathrm{C}$ : Phase, kinetics and mechanism with reaction time. ChemistrySelect 3, 13010-13016.

Liu, S.K., Han, C., Liu, J.M., 2019. Study of K-feldspar and lime hydrothermal reaction: Phase and mechanism with reaction temperature and increasing $\mathrm{Ca} / \mathrm{Si}$ ratio. Minerals 9, 46.

Locati, F., Marfil, S., Baldo, E., Maiza, P., 2010. $\mathrm{Na}_{2} \mathrm{O}, \mathrm{K}_{2} \mathrm{O}, \mathrm{SiO}_{2}$ and $\mathrm{Al}_{2} \mathrm{O}_{3}$ release from potassic and calcic-sodic feldspars into alkaline solutions. Cement Concrete Res. 40, 1189-1196.

Ma H.W., Yang J., Su S.Q., Liu M.T., Zheng H., Wang Y.B., Qi H.B., Zhang P., Yao W.G., 2015. 20 years advances in preparation of potassium salts from potassic rocks: A review. Acta Geologica Sinica (Eng. Ed.) 89, 2058-2071.

Marry, V., Rotenberg, B., Turq, P., 2008. Structure and dynamics of water at a clay surface from molecular dynamics simulation. Phys. Chem. Chem. Phys. 10, 4802-4813.

Martin, J.M., Vacher, B., Ponsonnet, L., Dupuis, V., 1996. Chemical bond mapping of carbon by image-spectrum EELS in the second derivative mode. Ultramicroscopy $65,229-238$.

Nesbitt, H.W., Muir, I.J., 1988. SIMS depth profiles of weathered plagioclase, and processes affecting dissolved Al and Si in some acidic soil conditions. Nature 334, 336-338.

Norberg, N., Neusser, G., Wirth, R., Harlov, D., 2011. Microstructural evolution during experimental albitization of K-rich alkali feldspar. Contrib. Mineral. Petrol. 162, 531-546.

Nugent, M.A., Brantley, S.L., Pantano, C.G., Maurice, P.A., 1998. The influence of natural mineral coatings on feldspar weathering. Nature 395, 588-591.

O'Neil, J.R., Taylor, H.P.J., 1967. The oxygen isotope and cation exchange chemistry of feldspars. Amer. Mineral. 52, 14141437.

Parker, S.C., de Leeuw, N.H., Bourova, E., Cooke, D.J., 2001. Molecular Modeling Theory: Applications in the Geosciences. In: Cygan, R.T., Kubicki, J.D. (Eds.), Reviews in Mineralogy and Geochemistry, Geochemical Society and Mineralogical Society of America, 42, pp. 63-82.

Parsons, I., Lee, M.R., 2009. Mutual replacement reactions in alkali feldspars I: microtextures and mechanisms. Contrib. Mineral. Petrol. 157, 641-661. 
1302

1303

1304

1305

1306

1307

1308

1309

1310

1311

1312

1313

1314

1315

1316

1317

1318

1319

1320

1321

1322

1323

1324

1325

1326

1327

1328

1329

1330

1331

1332

1333

1334

1335

1336

1337

1338

1339

1340

1341

1342

1343

1344

1345

1346

1347

1348

1349

1350

1351

1352

1353

1354

1355

1356

1357

1358

1359

1360

Parsons, I., Magee, C.W., Allen, C.M., Shelley, J.M.G., Lee, M.R., 2009. Mutual replacement reactions in alkali feldspars II: trace element partitioning and geothermometry. Contrib. Mineral. Petrol. 157, 663-687.

Petit, J.-C., Dran, J.-C., Schott, J., Della Mea, G., 1989. New evidence on the dissolution mechanism of crystalline silicates by $\mathrm{MeV}$ ion beam techniques. Chem. Geol. 76, 365-369.

Petit, J.-C., Dran, J.-C., Della Mea, G., 1990a. Energetic ion beam analysis in the Earth sciences. Nature 344, $621-626$.

Petit, J.-C., Della Mea, G., Dran, J.-C., Magonthier, M.-C., Mando, P.A., Paccagnella, A., 1990b. Hydrated layer formation during dissolution of complex silicate glasses and minerals. Geochim. Cosmochim. Acta 54, 1941-1955.

Putnis, A., 2002. Mineral replacement reactions: from macroscopic observations to microscopic mechanisms. Mineral. Mag. 66, 689-708.

Putnis, A., 2009. Mineral replacement reactions. In: Oelkers, E.H., Schott, J. (Eds.), Reviews in Mineralogy and Geochemistry, Mineralogical Society of America,70, pp. 87-124.

Putnis, A., 2014. Why mineral interfaces matter. Science 343, 1441-1442.

Putnis, C.V., Mezger, K., 2004. A mechanism of mineral replacement: Isotope tracing in the model system $\mathrm{KCl}-\mathrm{KBr}-\mathrm{H}_{2} \mathrm{O}$. Geochim. Cosmochim. Acta 68, 2839-2848.

Putnis, C.V., Tsukamoto, K., Nishimura, Y., 2005. Direct observations of pseudomorphism: compositional and textural evolution at a fluid-solid interface. Amer. Mineral. 90, 1909-1912.

Robin, E., 2017. Method for the determination of the mass thickness and the composition of a zone of an object using an electron beam and measurements of X-ray intensities. France patent EP 3032244 B1.

Ruiz-Agudo, E., Putnis, C.V., Putnis, A., 2014. Coupled dissolution and precipitation at mineral-fluid interfaces. Chem. Geol. 383, 132-146.

Ruiz-Agudo, E., Putnis, C.V., Rodriguez-Navarro, C., Putnis, A., 2012. Mechanism of leached layer formation during chemical weathering of silicate minerals. Geology 40, 947-950.

Schweda, P., Sjöberg, L., Södervall, U., 1997. Near-surface composition of acid-leached labradorite investigated by SIMS. Geochim. Cosmochim. Acta 61, 1985-1994.

Skorina, T., Allanore, A., 2015. Aqueous alteration of potassium-bearing aluminosilicate minerals: from mechanism to processing. Green Chem. 17, 2123-2136.

Su, S.Q., Ma, H.W., Chuan, X.Y., 2015. Hydrothermal decomposition of K-feldspar in $\mathrm{KOH}-\mathrm{NaOH}-\mathrm{H}_{2} \mathrm{O}$ medium. Hydrometallurgy 156, 47-52.

Teng, H.H., Fenter, P., Cheng, L., Sturchio, N.C., 2001. Resolving orthoclase dissolution processes with atomic force microscopy and X-ray reflectivity. Geochim. Cosmochim. Acta 65, 3459-3474.

Thomä, S.L.J., Krauss, S.W., Eckardt, M., Chater, P., Zobel, M., 2019. Atomic insight into hydration shells around facetted nanoparticles. Nature Commun. 10, 995.

Thomassin, J.-H., Le Coustumer, P., Patrier, P., 1995. Mineralogy and ultrastructure of some alteration products of Yamamoto-86032 meteorite. Proc. NIPR Symp. Antarc. Meteorites 8, 185-193.

van der Pluijm, B.A., Lee, J.H., Peacor, D.R., 1988. Analytical electron microscopy and the problem of potassium diffusion. Clays Clay Minerals, 36.

Villa, I.M., 2016. Diffusion in mineral geochronometers: Present and absent. Chem. Geol. 420, 1-10.

Watanabe, M., Williams, D.B., 2006. The quantitative analysis of thin specimens: a review of progress from the CliffLorimer to the new $\zeta$-factor methods. J. Micros. 221, 89-109. 
Wirth, R., 2004. Focused Ion Beam (FIB): A novel technology for advanced application of micro- and nanoanalysis in geosciences and applied mineralogy. Eur. J. Mineral. 16, 863-876.

Wirth, R., 2009. Focused Ion Beam (FIB) combined with SEM and TEM: Advanced analytical tools for studies of chemical composition, microstructure and crystal structure in geomaterials on a nanometre scale. Chem. Geol. 261, 217-229.

Yang, Y., Min, Y., Jun, Y.S., 2013. A mechanistic understanding of plagioclase dissolution based on Al occupancy and T-O

Yang, Y., Min, Y., Jun, Y., 2014a. Effects of Al/Si ordering on feldspar dissolution: part II. The pH dependence of

Yang, Y., Min, Y., Lococo, J., Jun, Y., 2014b. Effects of Al/Si ordering on feldspar dissolution: part I. Crystallographic control on the stoichiometry of dissolution reaction. Geochim. Cosmochim. Acta 126, 574-594.

Zhai, Y., Hellmann, R., Campos, A., Findling, N., Mayanna, S., Wirth, R., Schreiber, A., Cabié, M., Zeng, Q., Liu, S., Liu, J., 2021. Fertilizer derived from alkaline hydrothermal alteration of K-feldspar: A micrometer to nanometer-scale investigation of $\mathrm{K}$ in secondary reaction products and the feldspar interface. Applied Geochem.

Zhang, L., Lüttge, A., 2009. Theoretical approach to evaluating plagioclase dissolution mechanisms. Geochim. Cosmochim. Acta 73, 2832-2849. 
1399 Table 1. Chemical compositions of unaltered orthoclase samples based on XRF analyses (mass \%)

\begin{tabular}{|c|c|c|c|c|c|c|c|c|c|c|c|c|c|}
\hline Sample ID & Locality* & $\mathrm{SiO}_{2}$ & $\mathrm{TiO}_{2}$ & $\mathrm{Al}_{2} \mathrm{O}_{3}$ & $\mathrm{Fe}_{2} \mathrm{O}_{3}^{\dagger}$ & $\mathrm{MnO}$ & $\mathrm{MgO}$ & $\mathrm{CaO}$ & $\mathrm{Na}_{2} \mathrm{O}$ & $\mathrm{K}_{2} \mathrm{O}$ & $\mathrm{P}_{2} \mathrm{O}_{5}$ & LOI & Chemical formula \\
\hline CSY-1 (\#6) & Xinghe & 65.96 & 0.02 & 18.39 & 0.22 & 0.01 & 0.05 & 0.22 & 2.96 & 11.48 & 0.01 & 0.52 & $\mathrm{Na}_{0.26} \mathrm{~K}_{0.67} \mathrm{Ca}_{0.01} \mathrm{Al}_{0.99} \mathrm{Si}_{3.02} \mathrm{O}_{8}$ \\
\hline CSY-2 (\#3) & Xinghe & 66.04 & 0.03 & 18.31 & 0.21 & 0.00 & 0.08 & 0.14 & 1.00 & 13.29 & 0.02 & 0.82 & $\mathrm{Na}_{0.09} \mathrm{~K}_{0.78} \mathrm{Ca}_{0.01} \mathrm{Al}_{0.99} \mathrm{Si}_{3.04} \mathrm{O}_{8}$ \\
\hline CSY-3 (\#4) & Xinghe & 65.61 & 0.01 & 18.10 & 0.42 & 0.01 & 0.04 & 0.13 & 1.73 & 13.45 & 0.01 & 0.54 & $\mathrm{Na}_{0.15} \mathrm{~K}_{0.79} \mathrm{Ca}_{0.01} \mathrm{Al}_{0.98} \mathrm{Si}_{3.02} \mathrm{O}_{8}$ \\
\hline CHG-2 (\#2) & Chifeng & 66.16 & 0.03 & 18.07 & 0.31 & 0.00 & 0.18 & 0.30 & 2.63 & 11.66 & 0.01 & 0.78 & $\mathrm{Na}_{0.23} \mathrm{~K}_{0.68} \mathrm{Ca}_{0.01} \mathrm{Al}_{0.98} \mathrm{Si}_{3.03} \mathrm{O}_{8}$ \\
\hline CHG-12 (\#11) & Chifeng & 66.20 & 0.03 & 18.37 & 0.22 & 0.00 & 0.13 & 0.23 & 2.50 & 11.43 & 0.01 & 0.79 & $\mathrm{Na}_{0.22} \mathrm{~K}_{0.67} \mathrm{Ca}_{0.01} \mathrm{Al}_{0.99} \mathrm{Si}_{3.03} \mathrm{O}_{8}$ \\
\hline $\begin{array}{l}\dagger \text { total iron oxid } \\
\text { LOI: loss on ign }\end{array}$ & & & & & & & & & & & & & $\begin{array}{l}\text { *all localities are in } \\
\text { Inner Mongolia, China }\end{array}$ \\
\hline
\end{tabular}

1400

1401

1402

Table 2. BET $\left(\mathrm{N}_{2}\right)$ specific surface areas of orthoclase samples

\begin{tabular}{lcc} 
Sample ID & $\begin{array}{c}\text { BET unaltered } \\
\left(\mathrm{m}^{2} / \mathrm{g}\right)\end{array}$ & $\begin{array}{c}\mathrm{BET} \text { altered } \\
\left(\mathrm{m}^{2} / \mathrm{g}\right)\end{array}$ \\
\hline CSY-1C (\#6) & 3.8 & 13.7 \\
CSY-2C (\#3) & 2.1 & 12.4 \\
CSY-3C (\#4) & 4.9 & 13.3 \\
CHG-2C (\#2) & 2.8 & 11.1 \\
CHG-12C (\#11) & $*$ & $*$ \\
\hline
\end{tabular}

1403

* insufficient sample available 
Table 3. EDXS-measured elemental atomic ratios (unaltered orthoclase measured by XRF), and probable secondary phases- when identification was not possible, the phases are marked as CASH/CSH + carb (see text). Measurement locations in Figs. 4a-c, Fig. 9b, Fig. S7. np = nanoparticles

\begin{tabular}{|c|c|c|c|c|}
\hline $\begin{array}{l}\text { ortho \#6 } \\
\text { CSY-1C }\end{array}$ & $\mathrm{Al} / \mathrm{Si}$ & $\mathrm{K} / \mathrm{Si}$ & $\mathrm{Ca} / \mathrm{Si}$ & probable phase, remarks \\
\hline 1 & 0.34 & 0.24 & - & orthoclase \\
\hline 2 & 0.33 & 0.23 & 0 & orthoclase \\
\hline 3 & 0.31 & 0.17 & 0.01 & orthoclase \\
\hline 4 & 0.21 & 0.10 & 0.67 & amorphous (?) \\
\hline 5 & 0.53 & 0.30 & 0.02 & CASH \\
\hline 6 & 0.16 & 0.06 & 2.60 & $\mathrm{CASH} / \mathrm{CSH}+$ carb \\
\hline 7 & 0.19 & 0.01 & 0.72 & $\mathrm{CASH} / \mathrm{CSH}+$ carb \\
\hline 8 & 0.15 & 0.07 & 0.74 & $\mathrm{CASH} / \mathrm{CSH}+$ carb \\
\hline Fig. 9b & 0.30 & 0.72 & 0.32 & amorphous SAL \\
\hline unaltered & 0.33 & 0.22 & 0.003 & $\mathrm{Na}_{0.26} \mathrm{~K}_{0.67} \mathrm{Ca} 0.01 \mathrm{Al}_{0.99} \mathrm{Si}_{3.02} \mathrm{O}_{8}$ \\
\hline \multicolumn{5}{|l|}{$\begin{array}{l}\text { ortho \#4 } \\
\text { CSY-3C }\end{array}$} \\
\hline 9 & 0.11 & 0.12 & 1.11 & $\mathrm{CASH}+\mathrm{carb}$ \\
\hline 10 & - & - & - & resin \\
\hline 11 & 0.97 & 0.67 & 45.43 & calcite \\
\hline 12 & 0.35 & 0.23 & 0.001 & orthoclase \\
\hline 13 & 0.25 & 0.10 & 0.21 & amorphous (?) \\
\hline 14 & 0.15 & 1.23 & 13.42 & calcite \\
\hline 15 & 0.15 & 0.60 & 1.26 & $\mathrm{CASH} / \mathrm{CSH}+\mathrm{carb}+\mathrm{np}$ \\
\hline 16 & 0.10 & 0.09 & 1.10 & $\mathrm{CASH} / \mathrm{CSH}+\mathrm{carb}+\mathrm{np}$ \\
\hline 17 & 0.20 & 0.19 & 0.35 & amorphous (?) \\
\hline 18 & 0.12 & 0.005 & 0.27 & $\mathrm{CASH} / \mathrm{CSH}+$ carb \\
\hline 19 & 0.18 & 0.06 & 1.07 & $\mathrm{CASH} / \mathrm{CSH}+$ carb \\
\hline 20 & 0.34 & 0.25 & 0.002 & orthoclase \\
\hline unaltered & 0.32 & 0.26 & 0.003 & $\mathrm{Na}_{0.15} \mathrm{~K}_{0.79} \mathrm{Ca} 0.01 \mathrm{Al}_{0.98} \mathrm{Si}_{3.02} \mathrm{O}_{8}$ \\
\hline
\end{tabular}




\section{Figure Captions}

1413

1414 Fig. 1. Experimental protocol flow-chart for alkaline hydrothermal alteration process- see Materials and 1415 Methods, section 2.2 for details.

Fig. 2. Field emission scanning electron microscope (FESEM) secondary electron images of a polished section showing a primary orthoclase grain in cross section after hydrothermal alteration. a) Single grain (CSY-1C) surrounded by a rim of secondary crystalline phases. b) Close-up of rim (1) and globular 1420 entities (2-4) comprised of an amalgam of secondary phases, including amorphous material, calcite, and $\mathrm{CASH}+\mathrm{CSH}$ phases.

Fig. 3. Mono-elemental chemical maps measured by FESEM-EDXS (energy dispersive X-ray spectroscopy) of the same area as in Fig. 2b. The individual elements are indicated at the inner bottom corners of each image. The white arrows demarcate the interface between orthoclase and the alteration rim of secondary products. $\mathrm{K}, \mathrm{Ca}, \mathrm{Si}$, and $\mathrm{Al}$ are present at significant concentrations in most of the secondary globular entities (2-4), whereas $\mathrm{Ca}$ is particularly enriched in area 4 , and somewhat in the rim (1)- the high [Ca] in area 4 may point to enrichment in calcite. The majority of $\mathrm{C}$ is associated with resin, and its occurrence in areas 1-4 corresponds in large part to the presence of calcite.

Fig. 4. Focused ion beam (FIB) ultrathin sections imaged by high angle annular dark field-scanning transmission electron microscopy (HAADF-STEM). Rectangles indicate areas of EDXS analysesresults reported in Table 3. White arrows demarcate the orthoclase interface with secondary products. a) Cross sectional image reveals both amorphous (4) and crystalline secondary products (5-8) in close contact with an orthoclase grain (CSY-1C, nos. 1-3). Analysis area of rectangle 8 is only partially shown. The bladed crystals are likely to be tobermorite. b) Image showing orthoclase grain CSY-3C (12), calcite (white band, 11), other secondary crystalline phases (9), and resin (10). c) Image of same interface (CSY-3C) at different location; note the amorphous phase (13) with large pores contacting the orthoclase interface, the white band is likely a calcite layer (14). The small white particles (lower half of image, including analyzed areas 15,16 ) are presumed to be nano-sized precipitates.

1442 Fig. 5. a) Bright field (BF) TEM image of orthoclase grain (CSY-3C) and its interface (dashed white 1443 arrows) with secondary precipitates. Note the bladed crystals (tobermorite), the globular entity (bounded 1444 by 3 white arrows), and a band of calcite (opposing white arrows). The precipitate region is hydrated, as 
1446 also the abundant small black nano-size grains throughout the precipitate (these appear white in Fig. 4c).

1447 b) Deconvolved spectrum, obtained by selected area electron energy loss spectroscopy (EELS), serves to 1448 identify the calcite band, based on distinct C $K(289 \mathrm{eV}$ and $300 \mathrm{eV})$ and $\mathrm{Ca} L_{2,3}(348$ and $351 \mathrm{eV})$ edge 1449 structures.

1450

1451 Fig. 6. a) BF TEM image of orthoclase grain (CSY-1C) showing well-defined structural and mass1452 density interface (white arrows) between crystalline orthoclase and secondary precipitates. b) Ca $L_{2,3}$ 1453 energy filtered TEM (EFTEM) 3-window chemical map of the same region at slightly lower 1454 magnification. White areas are Ca-rich, and conversely, black areas are devoid of Ca, such as the 1455 orthoclase grain and resin. Note the sharp change in Ca concentration at the interface. Secondary 1456 precipitates also appear at right edge of image.

1458 Fig. 7. EDXS-derived ratios of $\mathrm{Na}, \mathrm{Na}+\mathrm{K}, \mathrm{K}$, and $\mathrm{Si}$, all normalized with respect to $\mathrm{Al}$, as function of 1459 total electron dose, measured with a Titan Themis TEM on various adjacent areas of unaltered 1460 orthoclase. The trends indicate that $\mathrm{K}$, and to a lesser extent $\mathrm{Na}$, are particularly mobile under a TEM 1461 electron beam, indicating that they should be measured with a total electron dose $<1.5 \mathrm{pA} \cdot \mathrm{s} \cdot \mathrm{nm}^{-2}$. These 1462 results explain anomalously low K values measured at orthoclase grain edges (see text, also Fig. 4a- area $14633)$.

1465 Fig. 8. HAADF-STEM image of a post-reaction orthoclase grain edge with an abutting amorphous 1466 surface altered layer (SAL). The relative thickness profile (in white- based on iterative calculations using 1467 elemental X-ray intensities) indicates a significant change in thickness at interface between the 2 phases. 1468 This image and the accompanying EDXS chemical profiles were obtained with a total electron dose = $14691.4 \mathrm{pA} \cdot \mathrm{s} \cdot \mathrm{nm}^{-2}$. The 4 elemental ratio profiles reveal quite different behaviors. The K/Al ratio shows a 1470 sudden jump right at the interface, whereas the $\mathrm{Na} / \mathrm{Al}$ ratio remains constant in both phases. The $\mathrm{Si} / 3 \mathrm{Al}$ 1471 and $\mathrm{O} / 8 \mathrm{Al}$ profiles remain roughly constant within the orthoclase (ratios $\approx 1$ ), but at the interface the 1472 ratios suddenly start to fluctuate- this may be due to pores or other inhomogeneities in the SAL. At 1473 distances further away from the interface $(<-30 \mathrm{~nm})$, both ratios show a fluctuating but monotonic 1474 increase.

1476 Fig. 9. TEM images of the same area as in Fig. 8, but slightly enlarged and cropped. a) HAADF-STEM 1477 image showing a sharp mass-density interface (white arrows) between orthoclase (CSY-1C) and an 1478 amorphous SAL. Note the presence of the large pore in the SAL. b) Superposed HAADF-STEM image 
1479 and EDXS chemical maps of $\mathrm{K}, \mathrm{Ca}$, and $\mathrm{Si}$ (scale bar $=50 \mathrm{~nm}$, applies to panels a) and b). The abrupt 1480 chemical discontinuity between the orthoclase and the SAL (white arrows) is coincident with the sharp 1481 mass-density change. The interface is in particular demarcated by the very sharp change in $\mathrm{Si}$ 1482 concentration (blue). The amorphous SAL contacting the orthoclase is particularly K-rich, while further 1483 away it is distinctly enriched in Ca. The rectangle demarcates where an average chemical composition of 1484 the precipitate was determined by EDXS- see text and Table 3). c) Individual elemental EDXS maps1485 note the extremely sharp, step function-like drop in Si and Al at the orthoclase (or)- SAL boundary. The 1486 Ca map indicates that this element did not penetrate the orthoclase structure.

Fig. 10. Oriented high-resolution TEM (HRTEM) image showing nm-sharp structural interface between 1490 orthoclase (note lattice fringes) and amorphous phase. Image taken on the same interface as in preceding 1491 figure (orthoclase CSY-1C). 